\title{
Costly Financing, Optimal Payout Policies and the Valuation of Corporate Debt ${ }^{1}$
}

\author{
Viral Acharya \\ New York University
}

\author{
Jing-zhi Huang \\ Penn State University
}

Rangarajan Sundaram

New York University

\author{
Marti Subrahmanyam \\ New York University
}

July 31,2000

\footnotetext{
${ }^{1}$ Acharya, Subrahmanyam, and Sundaram are at the Department of Finance, Stern School of Business, New York University, New York, NY 10012. Their respective e-mail addresses are vacharya@stern.nyu.edu, msubrahm@stern.nyu.edu and rsundara@stern.nyu.edu. Huang is at the Smeal School of Business, Penn State University, University Park, PA 16802; E-mail:jxh56@psu.edu.
} 


\begin{abstract}
We present a cash-flow based model of corporate debt valuation that incorporates two novel features. First, we allow for the separation and optimal determination of the firm's debt-service and dividend policies; in particular, the firm is allowed to maintain cash reserves to meet future debt obligations. Second, our model admits the possibility that raising resources through issuance of new equity could be a costly procedure. In contrast, much of the previous literature has considered only dividend policies that are the "residual" consequences of debt-service policy, and has assumed new equity issuance costs are either zero or infinite.

We provide an analytical characterization of equilibrium behavior in our model. Numerical analysis of the equilibrium reveals that our model predicts substantially higher yield spreads than the canonical Merton-type model. More importantly, we find that the two novel features of our model are crucial determinants of not only the overall spreads that result but also of the marginal impact of allowing for debt-service to be strategic. Specifically: (a) assuming residual rather than optimal dividend policies can result in a significant upward bias in the yield spreads predicted by the model; (b) the size of this bias depends in a central way on the costs of equity issuance; (c) the marginal impact of strategic debt-service is substantial, in general, only for low equity-issuance costs, and (d) under optimally-determined dividends, strategic debt-service can actually result in a narrowing of yield spreads. In summary, our results indicate that endogenizing dividend policy and allowing for equity-issuance costs can enhance the model's content substantially, while ignoring these factors could introduce non-trivial biases into the valuation.
\end{abstract}


Optimal Dividends \& Risky Debt Valuation ................................... 1

\section{Introduction}

An extensive literature in finance has built on Merton's [32] model for the valuation of corporate debt that is subject to the risk of default. Merton's original framework considers a firm with equity and zero-coupon debt as claims, and prices these claims under an exogeneously given process for the value of the firm's assets. The paper makes some simplifying assumptions. Intermediate cash flows are not modelled. It is assumed that liquidation of the firm is costless. It is further assumed that the absolute priority rule (APR) is strictly observed in the event of default, i.e., bondholders are paid in full before equityholders get anything. These simplifications are analytically advantageous, but they come at a steep cost: most importantly, the model generates yield spreads that are too small in relation to observed levels. Motivated by this discrepancy, subsequent research has generalized the Merton model in many ways; a review of the literature may be found in Section 2.

In a pair of striking recent papers, Anderson and Sundaresan [3] and Mella-Barral and Perraudin [30] propose models that extend Merton's framework in two important directions. First, the papers explicitly introduce periodic cash flows as the source of firm value and as the driving force behind the firm value process. This enables drawing a distinction between default and liquidation. Second, both papers allow for strategic debt-service, i.e., for equityholders to underperform on their debt-service obligations (even when there is sufficient cash available to meet these obligations) if this underperformance enhances equity value. ${ }^{1}$ Thus, in addition to "liquidity defaults" — which arise when there is insufficient cash to meet debt service obligations - "strategic defaults" are also now possible in the model; this enables endogeneization of equilibrium departures from the APR. It is shown that in the presence of liquidation costs, these richer specifications lead to equilibrium spreads that are substantially wider than in the original Merton [32] model and are closer to observed levels.

Despite these appealing features, the papers make two assumptions that warrant closer scrutiny. First, both papers require that all cash flows generated by the firm in each period be paid out completely to claimholders; thus, any residual cash left after debt service is necessarily paid out as dividends to equityholders. (We shall call this a residual dividend policy). Under such a policy, firms may not maintain cash reserves to meet future debt-service obligations. Second, with regard to the possibility of raising cash via issue of new equity, the papers make assumptions at opposite ends of the spectrum. Anderson and Sundaresan effectively assume this process is infinitely costly: new equity issuance in their model is prohibited altogether. At the other end, Mella-Barral and Perraudin take this process to be costless.

Neither assumption is completely satisfactory. Regarding the first, intuition suggests that it is important to allow for a separation of debt-service and dividend policies and for optimal determination of the latter rather than to assume that all residual cash is paid out as dividends. Casual and formal empirical evidence also support such separation; for example, Kalay [23] finds that firms do not pay equityholders the maximum amount of dividends they are allowed to given the

\footnotetext{
${ }^{1}$ The modelling of the default event and the the interaction of the different parties in bankruptcy has, of course, been a focus of corporate finance at least since Jensen and Meckling [21] and Myers [33]. Strategic debt service attempts to incorporate these considerations in a valuation setting.
} 
debt covenants they face. Concerning the second restriction, while it may be extreme to assume that new equity issuance is infinitely costly, it appears equally questionable to assume it is costless. Empirical documentation suggests that such costs are, in fact, substantial ${ }^{2}$ ignoring them would tend to delay liquidation and bias the value of equity upwards. Moreover, it is inconsistent to assume that the liquidation of assets is costly but the issue of new equity is not.

In this paper, we propose a generalization of these models that addresses these issues. First, our model does not require that the cash flow generated in each period be paid out in full to the claimholders. Rather, in addition to being used for debt-service and payment of dividends, we allow cash to simply be retained as reserves within the firm. Debt-service and dividend policies are set strategically and optimally. Second, our model admits the possibility that the issue of new equity could be costly. The firm chooses optimally the amount of equity to be issued given these costs. Finally, we retain the features of the earlier models that liquidation is costly and strategic debt-service is allowed. Thus, our paper combines five key aspects of the debt valuation problem:

1. The driving stochastic process is the cash flow from operations, not firm value itself.

2. The cash flow within each period can be used for debt service or dividend payments, or it can retained within the firm to create a cash reservoir for future payments.

3. Liquidation of assets is costly.

4. Additional resources can be raised by issuing new equity, but possibly at a cost.

5. Strategic underperformance of debt-service obligations by equityholders is permitted.

While subsets of these elements have been incorporated into previous models in the literature, our paper is the first to combine all five into a common framework, and, especially, to characterize optimal dividend and debt-service policies in the presence of costly new equity. This contribution is not just of theoretical interest: we show that the empirical implications of our model depend on the interaction between these features, with the two new ones playing an especially important role. Our main findings may be summarized as follows:

1. Our model predicts yield spreads that are generally substantially wider than an analog of the Merton model in our setting. Over a range of parametrizations, the difference in spreads is at least 125 basis points, and typically over twice that figure.

2. Assuming dividends are determined residually, rather than optimally, can bias yield spreads predicted by the model upwards by as much as 200 basis points or more. Intuitively, retained earnings under optimal dividends create a cushion that can substantially reduce the risk of the debt.

\footnotetext{
${ }^{2}$ For example, a study of equity issue in the US during the period 1990-94 by Lee, et al [25] considers the direct and indirect costs of raising new equity including underwriting costs and spreads, issue expenses, and the underpricing of the issue. They estimate that the direct costs average about $11 \%$ for initial public offerings and about $7 \%$ for seasoned equity offerings. It is safe to assume that the total costs of raising equity are substantial even for large corporations.
} 
Optimal Dividends \& Risky Debt Valuation .................................... 3

3. The actual size of the bias depends critically on the cost of issuing new equity:

(a) When the cost of new equity issuance is small, typically so too is the difference between the models. Intuitively, any cash shortfall may be made up by issuing new equity.

(b) When the cost is large, this alternative to retaining cash becomes expensive and often unprofitable, creating a significant gap between the predictions of the two models.

4. The marginal importance of allowing for debt service to be strategic depends in an essential way on both the cost of equity issuance and the dividend policy in place.

(a) Strategic debt service plays a significant role in determining overall spreads when the cost of issuing new equity is low, but at high costs its marginal impact is much diminished and often negligible.

(b) The direction of this impact depends on the dividend policy in place. Under a residual dividend policy, strategic debt service has a clearcut widening effect on spreads. However, under an optimal dividend policy, strategic debt service widens spreads when equityissuance costs are low, but could narrow them as these costs become high.

To summarize, these results indicate that endogeneizing the firm's dividend policy and allowing for equity-issuance costs can enhance the model's content substantially, while ignoring these factors could introduce non-trivial biases into the valuation.

The remainder of this paper is organized as follows. Section 2 surveys the literature and relates our model to previous work in the area. Section 3 describes our model and the game between debtholders and equityholders. Section 4 describes the structure of equilibrium in this model, while Section 5 provides an analytical characterization of optimal dividend policies for the case of zero-coupon debt. Section 6 specializes these results to a setting where the cash flows evolve according to a binomial process; this is the setting used by Anderson and Sundaresan [3] and is the discrete-time equivalent of the geometric Brownian motion assumption used in virtually all continuous-time models in this field. In this setting, we compute spreads under residual and optimal dividend policies and compare the results. Continuing this analysis, Section 7 compares spreads with and without strategic debt-service, while Section 8 compares our model to an analog of Merton's [32] model in our setting. Section 9 discusses the case of coupon debt. Section 10 concludes. All proofs omitted in the main body of the text may be found in the appendices.

\section{Related Literature}

The options characterization of corporate liabilities was first proposed by Black and Scholes [8] in their classic paper and elaborated upon by Merton [32]. The Merton framework posits a value process for a firm with no intermediate cash flows, and takes equity and zero-coupon debt as claims. In this setting, equity can be viewed as a simple European call option on the value of the firm, since default on the debt can occur only at maturity. Other salient features of Merton's model include 
Optimal Dividends \& Risky Debt Valuation .................................. 4

the absence of liquidation costs, and the strict observance of the absolute priority rule (APR) in the event of default (i.e., bondholders are paid in full before equityholders get anything).

Although the Merton model and its extensions such as Black and Cox [7], Geske [17], and Ho and Singer [19] are innovative in their characterization of risky corporate debt, they fall short of empirical validity. Several studies (e.g., Jones, et al [22]) have shown that yield spreads implied by Merton-type models are significantly lower than those observed in the market. Furthermore, violations of the APR and strategic renegotiation of debt contracts are widely observed in practice, contrary to the assumptions of the Merton model. ${ }^{3}$

In recent years, Merton's framework has been modified in several ways to make it more realistic and to bring its predictions in line with empirical evidence. ${ }^{4}$ Among these are (i) the introduction of intermediate or periodic cash flows as the source of firm value, which enables a distinction between default and liquidation, (ii) admitting costs of liquidation, (iii) allowing for renegotiation of contract terms between equity and debtholders, and (iv) modelling the violation of the APR, mainly as a consequence of renegotiation in the event of default. Several papers have examined a combination of the second and fourth features. Work by Leland [26] and Leland and Toft [27], among others, falls into this category. These models consider a stationary debt structure that allows for closed-form solutions and rich comparative statics. Other papers in this genre include Cooper and Mello [9], Longstaff [28], Longstaff and Schwartz [29], Kim, et al [24], Mello and Parson [31], and Nielsen, Saa-Requejo and Santa-Clara [34].

The possibility of renegotiation of debt contracts was introduced in Hart and Moore [18]. A central insight in their paper is that the existence of liquidation costs provides a motivation for equityholders to extract rents from the bondholders in the event of default. This feature was first integrated into a valuation setting by Anderson and Sundaresan [3] who used an extensiveform game-theoretic generalization of the Merton framework to analyze the interaction between equityholders and debtholders. Anderson, et al [4], Mella-Barral and Perraudin [30], and Pan [35] also develop similar ideas in the context of a perpetual bond. Huang [20] extends Anderson and Sundaresan to allow for costly equity financing.

In a recent paper, Fan and Sundaresan [14] analyze a model that addresses several of the issues raised in this paper. In particular, they also take the cash flow process as primitive, allow for costly liquidation, and assume that dividend and debt-service policies are set strategically and optimally. However, there are several important differences between their model and ours. First, although they consider external equity finance, their model does not consider the cost of raising resources in this manner. As a result, they do not consider the trade-off between using this costly alternative to avoid liquidation on the one hand, and incurring liquidation costs on the other; nor do they examine the impact of equity-issuance costs on optimal dividend policies. Second, they assume that retained cash is reinvested in the firm, changing the scale of the firm (more precisely, they presuppose a constant-returns-to-scale technology). Their model does not allow the firm to retain the

\footnotetext{
${ }^{3}$ See, for example, Alderson and Betker [1], Altman [2], Betker [5], Eberhart, Moore and Roenfeldt [13], Franks and Torous [15],[16], Warner [38], and Weiss [39].

${ }^{4} \mathrm{~A}$ second branch of the literature takes a "reduced-form" approach to pricing credit risk, and directly posits the stochastic process of default. See, e.g., Das and Sundaram [10] or Duffie and Singleton [12].
} 
Optimal Dividends \& Risky Debt Valuation ................................... 5

cash as reserves. This enables them to avoid the complications that come with path-dependence, since the current cash flow continues to act as an adequate description of the state of the world at any point. In contrast, our model presumes the scale of the firm is fixed; and that retained cash is held in a "reservoir" to make future payments to claimholders. Our approach is more in the spirit of Kalay [23] and Hart and Moore [18] who each argue, in different contexts, that it is optimal for the firm to maintain such reserves of cash.

In summary, several papers have considered cash flow-based models explicitly. Some of them have explored the consequences of the liquidation costs associated with the firm's assets and the strategic renegotiation between bondholders and equity holders. However, although the possibility of raising new equity has been considered in some papers, the cost of doing so has been ignored. In addition, the possibility of retaining cash within the firm in a reserve to meet future payments has also not been considered. This gap in the literature has important consequences. On the one hand, it leads to an unrealistic and asymmetric treatment of the firm which incurs costs of raising cash by liquidation, but not of raising equity. Thus, the models predict less liquidation than when such costs are incorporated, leading to an understatement of the risk-premium. However, countering this, the inability to maintain cash reserves increases the likelihood of forced liquidation, and, ceteris paribus, raises risk-premia. The overall direction of the bias cannot be predicted in general. Our paper develops a model in which these trade-offs can be considered and biases estimated for specific parametrizations. We turn now to a description of this model.

\section{The Model}

We consider a discrete-time setting with time periods indexed by $t=0,1,2, \ldots$ The riskless rate of interest per period is denoted $\rho$ and is taken to be a constant. It is also assumed that markets are free of arbitrage, so there exists an equivalent martingale measure $Q$ with respect to the riskless rate $\rho$. All stochastic processes and expectations defined in the sequel are with respect to $Q$.

At the center of our model is a group of homogeneous "equityholders" who have access to a project that will generate cash flows $\left\{\widetilde{f}_{t}\right\}$ into the indefinite future. At this stage, we place no restrictions on the structure of the cash flow process; in particular, it could be a binomial process as in Anderson and Sundaresan [3]. The present value, viewed from time- $t$, of all current and future cash flows is denoted by by $V_{t}$. Letting $\beta=(1+\rho)^{-1}$, we have

$$
V_{t}=f_{t}+\beta E_{t}\left[V_{t+1}\right]
$$

The project is partly financed by debt raised from a single homogeneous group of creditors. The debt contract has maturity $T$ and calls for the payment of an amount $c_{t}$ in each period $t$ upto $T$. The contract also provides for a contingent transfer of control rights or "liquidation" in the event that contractual obligations are not met in any period; this is at the option of the debtholders. Liquidation may not, however, be a costless process. We will denote by $L$ the cost of liquidating the firm. $L$ may depend on the value $A$ of the firm's assets at that point; we will assume, without loss of generality, that $L(A) \leq A$. 


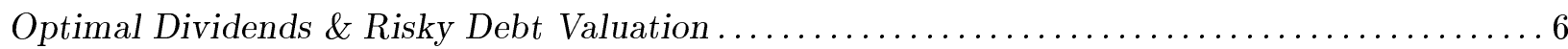

A central innovation in our paper concerns the treatment of cash flows. It is typical in the literature (see, e.g., Anderson and Sundaresan [3] or Mella-Barral and Perraudin [30]) to assume that at each $t$, any residual amount remaining from the cash flow $f_{t}$ after meeting debt service must be paid out as dividends to the equityholders (we shall call this a residual dividend policy). In particular, the firm is not allowed to retain cash to meet future debt-service obligations. Our paper allows for a separation of debt-service and dividend policies. We assume that in each period $t$, any cash left over after debt-service may be divided in any desired way between dividends paid to equityholders and cash retained by the firm as reserves. Retained cash is taken to be invested at the riskless rate $\rho$. Equityholders in our model choose the allocation of cash between its three uses - debt-service, dividends, and retained cash — optimally to maximize the value of equity.

Our model also allows equityholders to raise additional cash in any period through the issue of new equity. In contrast to much of the existing literature, however, we admit the possibility that this may be a costly procedure. Specifically, we assume that if the firm issues an amount $e$ of new equity at any point, it incurs a cost of $m(e) \geq 0$, where $m(\cdot)$ is a non-decreasing function; thus, the net amount of cash raised is $e-m(e)$. This structure nests as special cases the settings of Leland [26] and Mella-Barral and Perraudin [30] where new equity issue is assumed costless $(m(\cdot)=0)$; and Anderson and Sundaresan [3] where new equity issuance is taken to be prohibitively expensive $(m(e)=e)$.

\section{The Subgame at $t$}

We formalize all this by describing the subgame originating at $t, t \leq T$. Let $\phi_{t}$ denote the cash reserves entering period $t$, and let $f_{t}$ be the realized cash flow in period $t$. Taking into account this total cash availability of $\phi_{t}+f_{t}$, and the amount $c_{t}$ due on the debt in period $t$, equityholders first select a debt service amount $\xi_{t}$. If the offer $\xi_{t}$ meets the contractual obligation $c_{t}$, then debtholders must accept the offered amount. However, if $\xi_{t}<c_{t}$, the firm is technically in default and debtholders have the option of liquidating the firm. We discuss each of these possibilities and their consequences in greater detail below.

First, consider the case where $\xi_{t}<c_{t}$ and the debtholders reject the offer. In this event, the firm is liquidated. Its post-liquidation value is given by the value $V_{t}+\phi_{t}$ of its assets less the liquidation $\operatorname{cost} L_{t}$. (Note that the firm's time- $t$ asset value has two components: $V_{t}$ which denotes the value of current and future periodic cash flows and $\phi_{t}$, which denotes the cash reserves entering period t.) Let $D_{t}^{L}$ denote the amount recovered by the debtholders out of this post-liquidation value. $D_{t}^{L}$ may represent the whole or only a fraction of the face value of the total claims of the debtholders; the imperatives that go into the determination of $D_{t}^{L}$ are discussed below. As residual claimants, equityholders then receive any remaining portion of the post-liquidation value. Thus, the value of equity in liquidation is:

$$
\left[V_{t}+\phi_{t}\right]-L_{t}-D_{t}^{L}
$$

Alternatively, suppose debtholders accept the offer $\xi_{t}$. Two possibilities now arise. In the first, the available cash $\phi_{t}+f_{t}$ exceeds $\xi_{t}$. In this case, the proposed debt-service is made from available 
Optimal Dividends \& Risky Debt Valuation ................................. 7

cash. The equityholders then decide (i) how much equity $e_{t}$ (if any) is to be raised in period $t$, and (ii) the level of dividend service $\delta_{t}$. The issue of equity $e_{t}$ leaves the firm with a net cash holding (after debt-service) of $\phi_{t}+f_{t}-\xi_{t}+e_{t}-m\left(e_{t}\right)$. Thus, given the proposed dividend amount $\delta_{t}$, the retained cash in the firm at time $t+1$ is now

$$
\phi_{t+1}=(1+\rho)\left[\phi_{t}+f_{t}+e_{t}-m\left(e_{t}\right)-\xi_{t}-\delta_{t}\right] .
$$

The final remaining possibility is that the offer $\xi_{t}$ is accepted by the debtholders, but the cash holdings of the firm $f_{t}+\phi_{t}$ are insufficient to meet this offer. In this case, the firm must raise sufficient cash via issue of new equity to meet this difference. Taking into account the cost $m(\cdot)$ of raising new equity, this means the amount raised $e_{t}$ must satisfy

$$
\phi_{t}+f_{t}+e_{t}-m\left(e_{t}\right) \geq \xi_{t}
$$

If the firm is successful in raising the required equity, it makes the promised debt-service $\xi_{t}$, and then decides on a dividend amount $\delta_{t}$ from the remaining cash. Given these choices, the size of the cash reservoir entering period $t+1$ obtains as in (3.3). However, if the firm is not successful in raising the required equity, liquidation results with debtholders receiving $D_{t}^{L}$ and equityholders receiving the residual amount (3.2).

\section{Debt and Equity Values in Liquidation}

The amount $D_{t}^{L}$ received by debtholders in liquidation depends, in general, on a number of factors including (i) the value of the firm's assets at default time; (ii) the costs of liquidation; (iii) the debt structure under consideration; and (iv) the de facto treatment of the various parties in liquidation. Of these, the modeling of (iii) and-especially_-(iv) is non-trivial.

With regard to (iii), the maximum claim of the debtholders in liquidation is, in practice, dependent on the specific debt structure in question as well as on the laws governing default and bankruptcy. For coupon debt, this maximum is often set equal to the sum of the current coupon and the face value of the debt; with zero-coupon debt, the maximum claim is typically set equal to the face value of the debt adjusted for the time left to maturity.

Whether this maximum is actually received by the debtholders (even when there is enough postliquidation value to do so) depends on the liquidation process itself. Under the Absolute Priority Rule (APR), debtholders are given first claim on the post-liquidation value of the firm; thus, if $C_{t}$ denotes their maximum claim, they are entitled to receive

$$
D_{t}^{L}(\mathrm{APR})=\min \left\{C_{t}, V_{t}+\phi_{t}+e_{t}-m\left(e_{t}\right)-L_{t}\right\}
$$

It is customary in the literature to take liquidation payoffs as determined by the APR. For two reasons, we adopt a more flexible posture in this regard. First, it is well known that the APR is often violated in practice, so taking $D_{t}^{L}$ to be given by (3.5) may result in an overvaluation of debt. Second, the precise formulation of $D_{t}^{L}$ turns out to be unimportant for the theoretical analysis in 
Optimal Dividends \& Risky Debt Valuation ................................... 8

this paper; it plays a role only where we attempt to quantify the spreads generated by our model. Thus, at this stage, we assume simply that $D_{t}^{L}$ is an arbitrarily specified quantity lying between the natural admissible limits of zero and the post-liquidation value of the firm's assets:

$$
0 \leq D_{t}^{L} \leq V_{t}+\phi_{t}+e_{t}-m\left(e_{t}\right)-L_{t}
$$

At a later point, where we perform numerical comparisons of the spreads generated by our model with those obtained from others, we will follow much of the literature and assume that the APR holds, so that $D_{t}^{L}$ is given by $(3.5) .^{5}$

\section{Equilibrium}

The behavior of equityholders and debtholders is taken to be motivated solely by self-interest. The structure of the game and its parameters are all taken to be common knowledge. Equityholders choose debt-service and dividend policies to maximize the value of equity given debtholder behavior. Debtholders choose acceptance and rejection policies (that apply when offers fall short of contractual obligations) taking as given the equityholders' debt-service and dividend policies. A characterization of equilibrium behavior and analysis of equilibrium debt and equity values is the subject of the remainder of this paper.

\section{The Structure of Equilibrium}

The structure described above is an extensive-form game of perfect information. Subgame-perfect equilibria may be identified by backwards induction in the usual manner begining with the maturity date of the debt contract. We describe the general process here.

\section{Equilibrium in Period T}

Suppose the maturity period $T$ has been reached and the firm's performance on its debt-service obligations has not provoked liquidation thus far. At $T$, given the cash reserves $\phi_{T}$, the period- $T$ cash flow $f_{T}$, and the amount due on the debt $c_{T}$, the equityholders select a debt service amount $\xi_{T}$. If $\xi_{T} \geq c_{T}$, the debtholders accept payment and the game effectively ends, since the firm becomes an all-equity firm. However, if $\xi_{T}<c_{T}$, the debtholders must decide whether to accept it (and receive $\xi_{T}$ ) or force liquidation of the firm (and receive the liquidation payoff $D_{T}^{L}$ ). It is immediate that the offer $\xi_{T}$ will be accepted if and only if

$$
\xi_{T} \geq D_{T}^{L}
$$

Expression (4.1) implies that the less debtholders expect to receive in liquidation, the more willing they will be to accept underperformance of debt-service obligations.

\footnotetext{
${ }^{5}$ A superior alternative might be to take $D_{t}^{L}$ to be some fraction $\alpha \in[0,1]$ of (3.5) with $\alpha$ signifying the relative powers of the two parties in liquidation. The precise modeling of liquidation payoffs is, however, peripheral to the purposes of this paper; thus, we stick to the APR formulation.
} 
Now, conditional on making an acceptable offer, it is in equityholders' interest to make the smallest acceptable offer, which is $D_{t}^{L}$. This gives rise to two possibilities: (i) the available cash $\phi_{T}+f_{T}$ suffices for this purpose; (ii) the available cash is insufficient.

In case (i), it is clearly optimal for equityholders to make the offer $\xi_{T}=D_{T}^{L}$ and for debtholders to accept. Thus, the time- $T$ value of debt (denoted $V_{T}^{D}$ ) is the liquidation value $D_{T}^{L}$; and the time- $T$ value of equity (denoted $V_{T}^{E}$ ) is the residual value of the firm's assets:

$$
\begin{aligned}
V_{T}^{D} & =D_{T}^{L} \\
V_{T}^{E} & =V_{T}+\phi_{T}-D_{T}^{L}
\end{aligned}
$$

In case (ii), since the available cash $\phi_{T}+f_{T}$ is less than $D_{T}^{L}$, the difference $D_{T}^{L}-\phi_{T}-f_{T}$ must be raised via issue of new equity if liquidation is to be avoided. However, raising new equity could itself be a costly process, so this may not be a profitable choice for equityholders seeking to maximize the value of their equity. Specifically, let $e_{T}^{\min }$ denote the minimum amount of cash that must be raised in the form of new equity if liquidation is to be avoided:

$$
e_{T}^{\min }=\min \left\{e \geq 0 \mid \phi_{T}+f_{T}+e-m(e) \geq D_{T}^{L}\right\}
$$

Intuition suggests it is optimal for the equityholders to issue this new equity only if the costs $m\left(e_{T}^{\min }\right)$ of doing so are less than the liquidation costs $L_{T}$ that would be incurred otherwise. We show this to be true:

Proposition 4.1 Suppose $f_{T}+\phi_{T}<D_{T}^{L}$. If $m\left(e_{T}^{\min }\right) \leq L_{T}$, it is optimal for equityholders to avoid liquidation by raising new equity. The time-T values of debt and equity are

$$
\begin{aligned}
& V_{T}^{D}=D_{T}^{L} \\
& V_{T}^{E}=V_{T}+\phi_{T}-D_{T}^{L}-m\left(e_{T}^{\min }\right)
\end{aligned}
$$

If $m\left(e_{T}^{\min }\right)>L_{T}$, then it is optimal for equityholders to have the firm liquidated, and we have

$$
\begin{aligned}
& V_{T}^{D}=D_{T}^{L} \\
& V_{T}^{E}=V_{T}+\phi_{T}-D_{T}^{L}-L_{T}
\end{aligned}
$$

Proof Suppose the equityholders raise a level of equity $e_{T} \geq e_{T}^{\min }$. Then, the cash available to the firm is $\phi_{T}+f_{T}+e_{T}-m\left(e_{T}\right)$. Net of debt-service $D_{T}^{L}$, therefore, the value of the firm's assets is $V_{T}+\phi_{T}+e_{T}-m\left(e_{T}\right)-D_{T}^{L}$. Of this quantity, $e_{T}$ represents the value of the new equity raised in period $T$, so the value of the "existing" equity is simply

$$
V_{T}+\phi_{T}-m\left(e_{T}\right)-D_{T}^{L}
$$


Since $m(\cdot)$ is a monotone increasing function, it is apparent from (4.6) that conditional on raising enough new equity to avoid liquidation, the value of existing equity is maximized by raising the minimum required amount $e_{T}^{\min }$, so that existing equity has the time- $T$ value

$$
V_{T}+\phi_{T}-m\left(e_{T}^{\min }\right)-D_{T}^{L}
$$

On the other hand, if the equityholders opt not to raise new equity, liquidation results and the value of equity in liquidation is simply

$$
V_{T}+\phi_{T}-L_{T}-D_{T}^{L}
$$

A comparison of (4.6) and (4.8) establishes the required result.

\section{Remark: The Importance of an Optimal Dividend Policy}

The importance of allowing for dividend policy to be optimally determined, rather than as the residual consequence of debt-service policy, can be illustrated using the time- $T$ payoffs derived above. For sharpness in exposition, we focus on the case where new equity is prohibitively costly to issue. In this case, depending on the cash available entering period $T$, payoffs are given by either (4.2) or (4.5). The discussion easily extends to the general case of costly equity.

A comparison of (4.2) and(4.5) reveals that time- $T$ equity value $V_{T}^{E}$ has a discontinuity at the point where $\phi_{T}+f_{T}=D_{T}^{L}$. This discontinuity provides a fundamental motivation for retaining cash in the firm rather than paying it out as dividends. Specifically, note from (4.2) and (4.5) that, except at the point of discontinuity, $V_{T}^{E}$ has a slope of at most +1 in $\phi_{T}$; in words, retaining an extra dollar in the firm today results, in present value terms, in a gain in equity value of at most a dollar tommorow. At the point of discontinuity, however, the value of equity registers a jump increase of $L_{T}$, representing liquidation cost "savings" from having enough cash to meet minimum debt-service requirements. Thus, a policy of retaining more cash in the firm at time $T-1$ as reserves may be worthwhile if it avoids liquidation in a sufficiently high-probability state.

Allowing for an optimal dividend policy enables equityholders to take advantage of this discontinuity. Ipso facto, it also reduces the probability of liquidation in equilibrium compared to a residual dividend policy. Indeed, it is not hard to see that the only situations in which it is optimal to pay out all surplus cash as dividends in period $T-1$ are where either (i) there are no liquidation $\operatorname{costs}\left(L_{T} \equiv 0\right)$, or (ii) there is no cost of raising new equity $(m(\cdot) \equiv 0){ }^{6}$

\footnotetext{
${ }^{6}$ In the former case, there are no benefits to carrying reserves (since there are no liquidation charges to be avoided) but there could be an important cost: if a liquidation state is reached, debtholders have first claim on the firm's assets including the reserves. In the latter case, the absence of equity-issuance costs enables equityholders to raise exactly the amount of money required in a given state to avoid liquidation in that state provided it is profitable to do so. In contrast, since reserves are chosen ex-ante, they have the disadvantage that there may be "too much" cash ex-post: if a state is reached where is is optimal to liquidate the firm, debtholders will have first claim on these reserves.
} 


\section{Equilibrium in Period $T-1$}

We return to the description of equilibrium. Consider period $T-1$, and let $\phi_{T-1}$ and $f_{T-1}$ denote, respectively, the cash reserves at the begining of $(T-1)$ and the realized cash flow in $(T-1)$. Let $\xi_{T-1}$ denote the debt-service offered by the equityholders. If $\xi_{T-1}$ meets the amount $c_{T-1}$ due on the debt, the offer is necessarily accepted; if not, it may be rejected at the debtholders' option.

If the offer is rejected, the firm is liquidated and the debt and equity values resolve as

$$
\begin{aligned}
& V_{T-1}^{D}=D_{T-1}^{L} \\
& V_{T-1}^{E}=V_{T-1}+\phi_{T-1}-D_{T-1}^{L}-L_{T-1}
\end{aligned}
$$

If the offer is accepted, equityholders must then decide on (i) how much cash $e_{T-1}$ is to be raised through the issue of new equity, and (ii) the dividend payout $\delta_{T-1}$ in period $T-1$. In particular, in the event that the initial available cash $\phi_{T-1}+f_{T-1}$ is insufficient to meet the proposed debt-service payment of $\xi_{T-1}$, the new equity issue must at least satisfy

$$
\phi_{T-1}+f_{T-1}+e_{T-1}-m\left(e_{T-1}\right) \geq \xi_{T-1} .
$$

If the firm is unable to raise enough cash to meet the promised payment, then liquidation results and the parties receive the payoffs (4.9). Otherwise, the proposed payments are made, and debt and equity values are realized as

$$
\begin{aligned}
& V_{T}^{D}=\xi_{T-1}+\beta E_{T-1}\left[V_{T}^{D}\right] \\
& V_{T}^{E}=\delta_{T-1}+\beta E_{T-1}\left[V_{T}^{E}\right]
\end{aligned}
$$

where $E_{T-1}[\cdot]$ denotes expectation (under $Q$ ) of time- $T$ values conditional on all information at the end of period $T-1$, including the choices of $\xi_{T-1}, \delta_{T-1}$, and $e_{T-1}$.

From (4.9) and (4.10), it is optimal for debtholders to accept the offer $\xi_{T-1}$ if and only if the debt value from continuation (4.10) exceeds that from liquidation (4.9). Taking this into account, equityholders pick a debt-service offer, and values for new equity issuance and dividend payout, to maximize the time $T-1$ value of existing equity.

\section{Remark: The Interdependence of Debt-Service and Dividend Policies}

A comparison of (4.9) and (4.10) reveals the intuitively appealing point that the equilibrium acceptance policy depends on the dividend policy adopted by the equityholders. Specifically, the expectation of continuation debt value in (4.10) depends on the anticipated dividend policy of the equityholders: ceteris paribus, a higher current dividend payout lowers retained cash holdings entering period $T$, and thereby lowers continuation debt values. This makes liquidation relatively more attractive. Put differently, this means strategic underperformance of debt $\left(\xi_{T-1}<c_{T-1}\right)$ must be combined with a "low" dividend policy to make it acceptable to debtholders. From a 
modelling standpoint, this observation further underlines the need to separate dividend and debtservice policies. It is also in line with dividend covenants observed in practice (see, e.g., Smith and Warner [36]). Indeed, since the firm's dividend policy in our model is chosen subsequent to debt-service, the only way for the equityholders to credibly commit to a low level of dividends is precisely through the use of binding restrictions on dividend policy in the debt contract.

\section{Equilibrium in Periods $t<T-1$}

Equilibrium in earlier periods obtains in exactly the same way as in period $T-1$ using an induction argument. This completes the description of the game's equilibrium.

\section{Zero-Coupon Debt}

A special structure of particular interest is zero-coupon debt, which involves only a single lump-sum payment at maturity $T$ :

$$
c_{t}= \begin{cases}0, & t<T \\ \bar{c}, & t=T\end{cases}
$$

The valuation of risky zero-coupon debt has been the focus of a number of papers begining with Merton [32]. In this section, we examine the implications of our model for this debt structure. In Section 5.1, we present an analytic characterization of the optimal dividend policy that results. Using this characterization, we examine, in Section 5.2, the qualitative direction of the biases that result when dividend policies are not chosen optimally, but are rather determined as residual consequences of debt-service policies. To complete the analysis, in Section 6 , we give quantitative expression to these biases, by comparing the spreads generated by our model to those obtaining from residual dividend policies for a range of parameterizations of the model.

\subsection{The Structure of Equilibrium with Zero-Coupon Debt}

As is evident from the description in Section 4, equilibrium behavior in our model could, in general, be analytically quite complex. It is interesting, therefore, that under zero-coupon debt the optimal dividend policy upto period $T-2$ is easily described:

Proposition 5.1 If debt has the zero-coupon form (5.1), then it is an optimal dividend policy to pay no dividends upto and including period $T-2$.

Proof See Appendix B.1.

Proposition 5.1, which is of particular use from a computational standpoint, re-emphasizes the importance of allowing for an optimal dividend policy. A simple intuitive argument underlies the 
result. Giving up a dollar of dividends in any period $t \leq T-2$ entails no present-value loss to equity holders if the dollar (plus interest at the rate $\rho$ ) will be returned as dividends in period $T-1$. Now, the only circumstance in which equityholders will choose to not pay out all accumulated cash as dividends in period $T-1$ is where equity value can be enhanced by retaining some cash in the firm because it helps avoid a costly cash shortfall in period $T$. Thus, the zero-dividend policy either leaves investors no worse off (if all accumulated cash is paid out in period $T-1$ ) or strictly better off (if the retained cash helps prevent costly liquidation or raising of new equity). Proposition 5.1 follows.

A natural question arising from Proposition 5.1 is: what is the optimal dividend policy in period $T-1$ ? In general, the answer will depend on the structure of the problem in question (the cash flow process, liquidation costs, etc). In two cases of interest, however, a precise answer may be provided. Suppose that either there are no liquidation costs, or there are no equity-issuance costs. In either of these situations, it is optimal to pay out the entire cash reserves as dividends in period $T-1$. (This was noted above in Section 4; see footnote 6 and the remarks leading to it.) Intuitively, in either case there is no gain to be made by equityholders in carrying cash from $T-1$ to $T$, but there is a possible loss: if liquidation occurs at $T$, debtholders have first claim on the firm's assets including the cash reserves. We summarize this as a proposition:

Proposition 5.2 Suppose either (a) there are no liquidation costs, or (b) equity may be raised costlessly. Then, it is an optimal policy to pay out as dividends in period $T-1$ all cash reserves available with the firm.

Combining Propositions 5.1 and 5.2 now provides us with the following corollary:

Corollary 5.3 Suppose either (a) there are no liquidation costs, or (b) equity may be raised costlessly. Then, residual dividend policies are fully optimal; that is, it is an optimal policy to pay out all cash flows as dividends in each period upto and including $T-1$.

Proof From Proposition 5.1, it is always optimal to pay no dividends up to and including period $T-2$, and to simply retain all cash flows up to that point as reserves. On the other hand, from Proposition 5.2, it is optimal, in the two situations identified in the statement of the corollary, to carry forward zero reserves from period $T-1$ to period $T$, i.e., to pay out the entire cash reserves as dividends in period $T-1$. From a present value standpoint, retaining all cash flows in the firm upto period $T-1$ and paying them out as dividends at that point is equivalent to paying out all cash flows as dividends as they occur.

Remark Corollary 5.3 hides an important asymmetry between liquidation costs and equityissuance costs. It is, in fact, true (and becomes apparent on a little reflection), that if equityissuance costs are zero, then-regardless of the liquidation cost structure or the specific debt structure in question - "residual dividend policies" are optimal; that is, it is optimal to pay out as dividends any cash left over after debt service at every point in time. However, under coupon debt, residual dividend policies may be strictly suboptimal even when liquidation is costless, if equity-issuance costs are high. See Example C.1 in Section 9. 


\subsection{The Valuation Impact of Optimal Dividend Policies}

It is apparent from the foregoing analysis that assuming a residual dividend policy would result in a mis-estimation of the values of debt and equity in the model. The following result elaborates on this point. The terms "higher" and "lower" in its statement are to be taken as referring to the corresponding weak inequalities $\geq$ and $\leq$.

Proposition 5.4 Let debt have the zero-coupon structure (5.1).

1. Suppose there are either (a) no liquidation costs, or (b) no costs of raising equity. Then, equity and debt values are the same under optimal and residual dividend policies.

2. Suppose liquidation costs are strictly positive and issuing new equity is costly. Then, the values of debt and equity under an optimal dividend policy are higher than under a residual dividend policy. In particular, the equilibrium spreads on debt are lower in the presence of an optimal dividend policy.

Proof See Appendix B.2.

Part 1 of Proposition 5.4 follows from Corollary 5.3. To see Part 2, note that equity values will obviously be higher under an optimal dividend policy, since allowing equity holders additional policy choices cannot lower their equilibrium value. Debt values will also be higher since the presence of cash reserves may benefit debt holders in the event of liquidation (by increasing their receipts from liquidation), but it cannot, in any circumstance, hurt them.

\section{Quantifying the Impact of Optimal Dividends}

In this section, we quantify the impact of allowing dividend policies to be chosen optimally (rather than as the residual consequence of debt-service policy) and the role played by equity-issuance costs in this regard. To this end, we adopt the zero-coupon debt structure of Section 5 and utilize the characterization of optimal dividend policies provided there.

A preliminary comment is in order here. It would perhaps be ideal to perform this comparison in a setting with a general debt structure. However, analytic results on the structure of equilibrium are hard to obtain in our model in the general case of coupon debt (see Section 9 for more on this issue). ${ }^{7}$ Indeed, even in the case of zero-coupon debt, Section 5 shows that optimal policies will exhibit a considerable degree of path dependence. Such path-dependence may inject greater realism into the model, but it also complicates analysis; in particular, numerical methods are required to identify equilibrium values.

\footnotetext{
${ }^{7}$ Our use of a simple debt structure is not special. Virtually the entire literature in this area has focussed either on zero-coupon debt, or - in the case of some continuous-time models —on debt structures involving a "continuous" coupon. In all cases, analytical tractability has been the guiding factor.
} 
We proceed in several steps. In Section 6.1, we describe a common framework, involving specific assumptions on the cash flow process, liquidation costs, etc., that forms the basis of our comparisons. Then, in Sections 6.2 and 6.3, we describe equilibrium under residual and optimal policies, respectively, in this common framework; this is a specialization and strengthening of the material of Section 5. Section 6.4 presents the parameter configurations used in our comparisons. For these configurations, equilibrium debt and equity values are simulated numerically under residual and optimal dividend policies. These are presented in Sections 6.5 and 6.6, respectively. The results are compared in Section 6.7.

Sections 7 and 8 build on this analysis in two directions. Section 7 looks at the marginal impact of strategic debt service, by examining equilibrium values with and without this possibility. Section 8 compares our results to an analog of Merton's model in our setting. Both sections use the common framework developed in Section 6.1; for comparability reasons, the parameter configurations used are also kept common to the extent possible.

\subsection{A Common Framework}

We use a binomial framework similar to the one in Anderson and Sundaresan [3], which in turn is a discrete-time version of the geometric Brownian motion process used by Merton [32], Leland [26], Mella-Barral and Perraudin [30], and others. The riskless rate of interest per period is presumed to be a constant $\rho>0$. The remaining structure is described below.

\section{The Cash Flow Process}

Cash flows evolve according to a multiplicative binomial process: if $f_{t}$ represents the realized cash flow in period $t$, the distribution of cash flows in period $t+1$ is given by

$$
\widetilde{f}_{t+1}= \begin{cases}u f_{t}, & \text { with probability } p \\ d f_{t}, & \text { with probability } 1-p\end{cases}
$$

Appendix A shows that under (6.1), the value process $\left\{V_{t}\right\}$ is proportional to the cash flow process:

$$
V_{t}=b^{-1} \cdot f_{t}
$$

with the constant of proportionality $b$ given by $b=[1-\beta(p u+(1-p) d)]$. Of course, from $(6.1)$ and (6.2), $V_{t}$ itself follows a binomial process with parameters $u$ and $d$ :

$$
\widetilde{V}_{t+1}= \begin{cases}u V_{t}, & \text { with probability } p \\ d V_{t}, & \text { with probability } 1-p\end{cases}
$$

Anderson and Sundaresan [3] arrive at expressions (6.1)-(6.3) using a somewhat different, but essentially equivalent, procedure. They posit the process (6.3) for firm value, and then assume 
that cash flows and firm value are related by (6.2) to arrive at the process (6.1) for cash flows. Expression (6.3) is also the discrete-time equivalent of the geometric Brownian motion process for firm value used by Merton [32], Leland [26], and others. However, Merton and Leland do not explicitly introduce or make use of cash flows in their models.

\section{Liquidation Costs}

We take the total liquidation cost $L$ to have the form $L=\ell_{0}+\ell_{1} A$, where $\ell_{0}$ is the fixed component of liquidation costs, $\ell_{1}$ the proportional component, and $A$ the total value of the firm's assets. If the firm never carries forward any cash reserves, we have $A=V$, where $V$ is the present value of the current and future periodic cash flows. If cash reserves are allowed and the firm has a current cash reservoir of $\phi$, then $A=V+\phi$. Observe that the effective post-liquidation value of the firm is $\max \{0, A-L\}$; for notational simplicity, we will henceforth denote this quantity by $(A-L)^{+}$.

\section{Equity-Issuance Costs}

The equity-issuance costs are also assumed to be linear: if the firm issues an amount $e$ of equity, the cost it incurs is $m_{0}+m_{1} e$, where $m_{0}, m_{1}$ are non-negative constants. Thus, the net receipts to the firm from issuing an amount $e$ of equity are $\left(1-m_{1}\right) e-m_{0}$.

\section{Payoffs in Liquidation}

The Absolute Priority Rule will be assumed to hold in equilibrium. If $\bar{c}$ denotes the face value of debt, then liquidation at maturity results in the debtholders receiving the payoff

$$
D_{T}^{L}(A P R)=\min \left\{\bar{c},(A-L)^{+}\right\},
$$

while equity-holders receive the residual amount $A-D_{T}^{L}(A P R)=\max \{0, A-L-\bar{c}\}$.

\subsection{Equilibrium under Residual Dividends}

In the residual dividends model, no cash reserves are maintained by the equityholders. Thus, if $f_{T}$ denotes the realized cash flow in period $T$, and $V_{T}=b^{-1} f_{T}$ the value of current and future cash flows, the cost of liquidating the firm at time $T$ is

$$
L_{T}=\ell_{0}+\ell_{1} \cdot V_{T}
$$

Consequently, the liquidation value to debtholders in period $T$ is given by

$$
D_{T}^{L}(A P R)=\min \left\{\left(V_{T}-L_{T}\right)^{+}, \bar{c}\right\}
$$


Now, if $f_{T} \geq D_{T}^{L}$, then it is optimal for equityholders to offer $D_{T}^{L}(A P R)$ as debt service, and debt and equity values resolve accordingly. However, if $f_{T}<D_{T}^{L}$, liquidation can only be avoided by raising equity of $e_{T}$, where $f_{T}+e_{T}-\left(m_{0}+m_{1} e_{T}\right)=D_{T}^{L}(\mathrm{APR})$, or

$$
e_{T}=\frac{1}{1-m_{1}}\left[D_{T}^{L}(A P R)-f_{T}+m_{0}\right]
$$

Let $m_{T}$ denote the cost of raising the equity level required to avoid liquidation:

$$
m_{T}=\left\{\begin{array}{cl}
m_{0}+m_{1} \cdot e_{T}, & \text { if } f_{T}<D_{T}^{L}(A P R) \\
0, & \text { otherwise }
\end{array}\right.
$$

Thus, given $V_{T}$, the period- $T$ values of equity and debt are

$$
\begin{aligned}
& V_{T}^{E}\left(V_{T}\right)=V_{T}-D_{T}^{L}(A P R)-\min \left\{L_{T}, m_{T}\right\} . \\
& V_{T}^{D}\left(V_{T}\right)=D_{T}^{L}(A P R) .
\end{aligned}
$$

In earlier periods, all available cash flow is paid out as dividends to the equity holders. Thus, given $V_{t}$, the period- $t$ values of debt and equity are given by

$$
\begin{aligned}
& V_{t}^{D}\left(V_{t}\right)=\beta\left[p V_{t+1}^{D}\left(u V_{t}\right)+(1-p) V_{t+1}^{D}\left(d V_{t}\right)\right] . \\
& V_{t}^{E}\left(V_{t}\right)=b V_{t}+\beta\left[p V_{t+1}^{E}\left(u V_{t}\right)+(1-p) V_{t+1}^{E}\left(d V_{t}\right)\right] .
\end{aligned}
$$

Together with a backwards-induction argument, expressions (6.9)-(6.12) complete the description of equilibrium in the residual dividends model.

\subsection{Equilibrium under Optimal Dividends}

The optimal dividend policy upto period $T-2$ was described in Section 5.1. We now describe the optimization problem that determines the choice of period- $(T-1)$ dividends. Let $\phi_{T-1}$ denote the cash reserves entering period $T-1$, and suppose $f_{T-1}$ is the realized cash flow in period $T-1$. The maximum cash reserves that the equity holders can carry into period $T$ is

$$
\phi^{\max }=(1+\rho)\left[\phi_{T-1}+f_{T-1}\right] .
$$

We will describe the value of equity that results if the cash reserves entering period $T$ are chosen to be $\phi$ for any given $\phi \in\left[0, \phi^{\max }\right]$. Maximizing this equity value over $\phi$ then delivers the optimal value of equity — and the optimal dividend level — in period $T-1$. To this end, observe, first, that given $\phi$, the dividend payment to equity holders in period $T-1$ is

$$
\delta_{T}=\phi_{T-1}+f_{T-1}-\beta \phi .
$$


Now, suppose the realized cash flow in period $T$ is $f_{T}$. Given $\phi, f_{T}$, and $V_{T}=b^{-1} f_{T}$, the cost of liquidating the firm in $T$ is given by

$$
L_{T}=\ell_{0}+\ell_{1} \cdot\left(V_{T}+\phi\right) .
$$

Consequently, the liquidation value to debtholders in period $T$ is given by

$$
D_{T}^{L}(A P R)=\min \left\{\left(V_{T}+\phi-L_{T}\right)^{+}, \bar{c}\right\}
$$

If the available cash $f_{T}+\phi$ exceeds $D_{T}^{L}$, it is optimal to offer $D_{T}^{L}$ to the debtholders and to raise no new equity. However, if $f_{T}+\phi<D_{T}^{L}$, liquidation can be avoided only by raising equity of $e_{T}>0$, where $e_{T}$ satisfies $f_{T}+\phi+e_{T}-\left(m_{0}+m_{1} e_{T}\right)=D_{T}^{L}(A P R)$, or:

$$
e_{T}=\frac{1}{1-m_{1}}\left[D_{T}^{L}(A P R)-f_{T}-\phi+m_{0}\right]
$$

Let $m_{T}$ denote the cost of raising the equity level required to avoid liquidation:

$$
m_{T}=\left\{\begin{array}{cl}
m_{0}+m_{1} \cdot e_{T}, & \text { if } f_{T}+\phi<D_{T}^{L}(A P R) \\
0, & \text { otherwise }
\end{array}\right.
$$

Then, given $\phi$ and $V_{T}$, the period- $T$ values of equity and debt resolve as

$$
\begin{aligned}
& V_{T}^{E}\left(\phi, V_{T}\right)=V_{T}+\phi-D_{T}^{L}-\min \left\{L_{T}, m_{T}\right\} . \\
& V_{T}^{D}\left(\phi, V_{T}\right)=D_{T}^{L} .
\end{aligned}
$$

Under (6.1), either $V_{T}=u V_{T-1}$ or $V_{T}=d V_{T-1}$. Using this, the time $T-1$ value of equity, conditional on $\phi$, is

$$
\delta_{T-1}+\beta\left[p V_{T}^{E}\left(\phi, u V_{T-1}\right)+(1-p) V_{T}^{E}\left(\phi, d V_{T-1}\right)\right]
$$

Equityholders now choose $\phi \in\left[0, \phi^{\max }\right]$ to maximize $(6.21)$. The maximized value of $(6.21)$ is, of course, the equilibrium time $T-1$ value of equity, given $V_{T-1}$ and $\phi_{T-1}$. Given the optimal choice $\phi^{*}$, moreover, the optimal dividend policy at $T-1$ is determined via (6.14). Finally, given $\phi^{*}$, the equilibrium debt value at $T-1$ is just

$$
V_{T-1}^{D}\left(V_{T-1}, \phi_{T-1}\right)=\beta\left[p V_{T}^{D}\left(\phi^{*}, u V_{T-1}\right)+(1-p) V_{T}^{D}\left(\phi^{*}, d V_{T-1}\right)\right] .
$$

For points in time $t<T-1$, the problem is much simpler. We have already seen that it is optimal to have a zero dividend policy upto $T-1$. Thus, the value of equity at time $t$ is simply the discounted expected value of equity at time $(t+1)$ given zero dividends. Values of debt are derived analogously. The initial values of debt and equity may thus be recoverd. 


\subsection{Numerical Analysis: The Parameter Values}

Having described the structure of equilibria under the two regimes, we proceed now to a numerical computation of these equilibrium payoffs for a wide range of parameterizations. In this subsection, we describe the parameter configurations used in this exercise. These configurations are also used in computing equilibrium values in Sections 7 and 8.

As in Anderson and Sundaresan [3], the initial firm value is normalized throughout to $V_{0}=1$, and the zero-coupon debt is taken to have a maturity of 10 years. Concerning the other parameters, we use a total of 486 different configurations:

1. Three values are considered for the variable cost of issuing equity: $m_{1} \in\{0,0.15,0.99\}$; the fixed cost $m_{0}$ is set to zero. The extreme values $m_{1}=0$ and $m_{1}=0.99$ correspond, respectively, to the assumptions of Mella-Barral and Perraudin [30] (zero equity-issuance costs), and Anderson and Sundaresan [3] (prohibitively high costs). The middle value of $m_{1}=0.15$ is a more realistic value given empirical evidence.

2. Three values are considered for the value of debt: $\bar{c} \in\{0.25,0.50,0.75\}$. Given the initial firm value of unity, these cover the range from relatively safe to risky debt.

3. Three values are considered for the fixed cost of liquidation $\left(l_{0}=0,0.10,0.20\right)$, and two for the variable cost $\left(l_{1}=0.25,0.35\right)$.

4. Three values are considered for the annualized volatility $\sigma$ of the $\left\{V_{t}\right\}$ process: $\sigma^{2} \in\{0.03,0.10,0.20\}$. These are the three values considered in Anderson and Sundaresan [3], and correspond to low, medium, and high volatility firms.

5. Three values are considered for the cash-flow-to-value constant: $b \in\{0.015,0.025,0.035\}$. These correspond, intuitively, to high, medium, and low price/earnings ratios.

Of course, we do not report equilibrium values for all the parameter combinations here. Parameter values for the 8 tables presented in this paper were chosen as a representative subset and, wherever relevant, also to highlight special features of the equilibrium process.

\subsection{Equilibrium Values under Residual Dividends}

Tables 1 and 2 summarize equilibrium payoffs under residual dividends for a number of parameter values. Table 1 considers a range of liquidation costs, equity-issuance costs, and face values of debt. The volatility $\sigma$ and the cash-flow-to-value proportion $b$ are held fixed in this table at their middle values. Complementing Table 1, Table 2 looks at equilibrium values as $b$ and $\sigma$ vary for fixed values for the other parameters.

Consider Table 1 first. The most prominent feature of this table is that equilibrium debt values - and, hence, spreads over the riskless rate $\rho$-are independent of the equity-issuance cost parameter $m_{1}$. This seemingly counterintuitive property obtains because under strategic debt 
service, debtholders receive only their reservation value in equilibrium (viz., the amount they obtain in liquidation), and this latter quantity is independent of equity-issuance costs under a residual dividend policy! (Importantly, this is not true in the optimal dividends model. There, as we will see, the size of the cash reserves $\phi$ - which affects liquidation payoffs of the debtholders-will depend in an essential manner on equity-issuance costs.)

Of course, equilibrium equity values are not independent of $m_{1}$ : they decline as $m_{1}$ increases. This is intuitive: although debtholders receive the same amount regardless of $m_{1}$, the cash flow $f_{t}$ will, in some states, be insufficient to make this payment, and it may be worthwhile for equityholders to raise the balance by issuing equity. The cost of issuing equity reduces equity value.

Tables 1 and 2 also exhibit some other interesting relationships, namely that equilibrium spreads increase with (i) an increase in liquidation costs, (ii) an increase in the face value $\bar{c}$ of the debt, (iii) an increase in the ratio $b$, and (iv) an increase in the volatility $\sigma$. The first of these is simply a consequence of the fact that debtholders only receive their liquidation payoffs in equilibrium, and higher liquidation costs reduce these liquidation payoffs. The second obtains from the fact that a higher face value $\bar{c}$ increases the risk of default. The third relationship is a little more subtle. Since the initial value $V_{0}$ is being held fixed at unity, a higher value for $b$ means more of this initial value is being realized as cash up front, and a correspondingly smaller amount is available at maturity of the debt; this increases the equilibrium spread. Lastly, an increase in volatility creates higher cash flows in "good" states (those at the top of the tree), but poorer ones in the "bad" states (those at the bottom of the tree). The upside gain from this increased volatility is limited since the debtholder does not benefit from increases in cash flows that are greater than the face value; however, the downside risk increases as cash flows in poor states fall further.

\subsection{Equilibrium Values under Optimal Dividends}

Tables 3 and 4 summarize equilibrium payoffs under optimal dividends for the same parameter configurations used in Tables 1 and 2, respectively.

One immediate consequence of allowing for dividend policies and cash reserves to be optimally chosen is that equilibrium behavior becomes very much more complex. Nowhere is this increased complexity better reflected than in the dependence of equilibrium spreads on equity-issuance costs. "In general," spreads decrease as equity-issuance costs increase; but in some cases, U-shaped behavior is witnessed with spreads first decreasing, then increasing, as $m_{1}$ increases. This behavior arises from a combination of factors. To avoid costly liquidation, equityholders face two options. They can transport cash as reserves across periods, or they can raise cash by issuing new equity as needed. The more the equity-issuance costs, the greater the incentive to avoid liquidation using cash reserves rather than new equity, so the greater the cash reserves carried. Since debtholders have first claim on these reserves in liquidation, this raises debtholders' liquidation values, hence their payoffs in equilibrium. Thus, spreads will, "in general," fall as equity-issuance costs increase.

However, unlike raising equity, carrying cash reserves has the disadvantage that the size of cash reserves is decided in advance, before the state of the world next period is realized. To see the 
problem this creates, consider a situation where even carrying the maximum reserves, liquidation cannot be avoided using just the reserves in one of the two states next period. If equity issuance costs are sufficiently high that new equity issuance is also not a profitable way to avoid liquidation, equityholders face a simple choice: carry forward enough reserves to avoid liquidation in the one state (and take the chance that in the "wrong" state these reserves will accrue to the debtholders first) or accept liquidation in both states. Intuitively, it is apparent that in some circumstances at least the latter may be preferable, in which case, of course, zero reserves become optimal. This means the reserves carried will be smaller than at lower equity costs where new equity issuance could have been used to avoid liquidation profitably. Moreover, as equity costs increase in size, the number of states at which liquidation cannot be avoided also increases, so zero reserves become optimal in more cases. This reduces liquidation payoffs to debtholders, leading to an increase in spreads and creating the U-shaped curve in equity-issuance costs.

Table 3 also shows that under optimal dividends, equilibrium spreads increase with increases in liquidation costs or the face value $\bar{c}$ of debt. Both features are consequences of the fact that under strategic debt service, debtholders only receive their reservation (i.e., liquidation) values in equilibrium. The first arises because an increase in liquidation costs lowers this reservation value. The second holds because an increase in $\bar{c}$ increases this reservation value by at most one-for-one, but in some states by less than that (see expression (6.4)). Similarly, Table 4 shows that spreads increase as the payout ratio $b$ increases or as volatility $\sigma$ increases. These phenomena hold for similar reasons as in the residual dividends case. ${ }^{8}$

\subsection{Comparison of Values and Spreads}

Table 5 summarizes the differences in equilibrium equity and debt values and spreads in the two models for the parameter values considered in Tables 1 and 3. At zero equity costs, Proposition 5.4 shows that there is no difference between the models since residual dividend policies are fully optimal. As equity costs start rising however, the models start diverging.

When $m_{1}=0.15$, equity values predicted by the optimal dividends model are higher by about $3 \%-5 \%$ than the values predicted by the residual dividends model. Debt values are also typically higher (as, indeed, they must be from Proposition 5.4), but there is greater variation here, with the differences being negligible in some cases and substantial in others. This behavior is reflected in the differences in spreads; at $m_{1}=0.15$, the table shows that the spreads between the models can be virtually identical for some parameterizations, but could also of the order of 30 basis points or more for others.

As equity costs continue to increase, the difference between the models becomes further exaggerated. An increase in equity costs decreases the profitability of avoiding costly liquidation by

\footnotetext{
${ }^{8}$ Actually, the arguments are a bit more complex here. Consider an increase in $b$, for instance. In this case, more of the firm value is realized up-front as cash, and correspondingly less in the future. Under residual dividends, this means automatically that there will be less cash to meet debt service at the time of maturity so spreads increase. Under optimal dividends, however, what matters is the size of the accumulated cash reserves that are feasible, and one has to check that these grow slower on average as $b$ increases.
} 
raising new equity. This increases the importance of cash reserves. Since such reserves are forbidden under residual dividend policies, "too much" liquidation occurs in this case, leading to lower equity and debt values and higher spreads. Table 5 shows that in the limit, when new equity issuance is prohibitively expensive, the difference in equilibrium values could be dramatic: equity values under optimal dividends could be $20 \%$ or more higher than under residual dividends, and spreads under the optimal dividends model could be well over 200 basis points lower than those under the residual dividends model.

To summarize, the difference between residual and optimal dividend policies depends in an essential way on equity-issuance costs. Where such costs do not exist, there is no difference in equilibrium values under the two policies. Where such costs are small or moderate, in some cases the difference can be small or even negligible; but in others, it can be very substantial. At very high equity-issuance costs, the difference is almost always significant, with residual dividend policies systematically undervaluing debt and overstating spreads.

\section{The Role of Strategic Debt Service}

Strategic underperformance of debt has been cited in the literature as a major determinant of overall spreads on risky debt (see, e.g., Anderson and Sundaresan [3], or Mella-Barral and Perraudin [30]). In this section, we examine the importance of strategic debt service to better understand its role in the presence of equity costs and optimal dividend policies. To this end, we compare the equilibria of Sections 6.5 and 6.6 to those that arise when debt service is non-strategic, i.e., when equityholders pay the full face value of the debt if either the cash reserves by themselves permit this, or the cost of raising sufficient equity for this purpose is less than the cost of liquidation. Tables 6 and 7 summarize our findings. The former looks at the residual dividends model and the latter at the optimal dividends model.

A perusal of Table 6 reveals two very strong properties. First, the difference in spreads is always positive, meaning that spreads are always higher in the residual dividends model when there is strategic debt service than when debt service is non-strategic. This is, of course, a consequence of the fact that debtholders only receive their reservation (i.e., liquidation) payoffs if debt-service is strategic, whereas in the non-strategic model, they always receive at least this much and typically more.

Secondly, there is a strong monotonic relationship between equity-issuance costs and the relative importance of strategic debt service: the difference in spreads between the strategic and nonstrategic models is very high when equity-issuance costs are low, but declines rapidly as these costs increase, becoming negligible in all cases when these costs become very high. Intuitively, as equity costs increase, it becomes progressively less profitable in general to meet debt obligations by raising equity, and this has the impact of reducing the marginal importance of strategic debt-service. To see how, consider the case where equity-issuance costs are prohibitively high, so liquidation can be avoided, if at all, only by meeting debt-service with current cash flows. For strategic debt service to even be a feasible option, two conditions must be met: (i) the cash flow in period $T$ must exceed 
the reservation value of the debtholders, and (ii) this latter quantity must be less than $\bar{c}$. If (i) fails, liquidation necessarily results, while if (ii) fails, debtholders must be offered at least $\bar{c}$, so there is no underperformance. In notational terms, this means for strategic debt-service to be feasible, we must have

$$
f_{T} \geq V_{T}-L_{T}
$$

Since $f_{T}$ is proportional to $V_{T}$, this may be rewritten as

$$
(1-b) V_{T} \leq L_{T}=\ell_{0}+\ell_{1} V_{T}
$$

When fixed costs of liquidation are small, inequality (7.2) is obviously hard to meet unless the level of variable costs is unrealistically high. This means strategic debt-service is unimportant at "most" terminal states, and the spreads will resemble those in the non-strategic model. ${ }^{9}$

Table 7 provides information on the importance of strategic debt service in the presence of an optimal dividend policy. The table shows that in some respects the impact is qualitatively the same as under residual dividends. For example, it is true here also (and for the same reason) that as equity costs increase, the relative importance of strategic play falls.

However, there are also two major differences. First, the quantitative impact of strategic debt service can diverge substantially. For instance, at $\bar{c}=0.50, m_{1}=0.15$ in the third panel in the two tables, the difference is 262 bps in Table 7 , but only 71 bps in Table 6 .

More importantly, however, there is even a qualitative difference. Under residual dividends, Table 6 showed that spreads always increased in the presence of strategic debt service. Under optimal dividends, Table 7 shows that strategic debt service could actually lead to a lower spread in some cases than non-strategic debt service! To see how, consider a situation with prohibitively high equity costs. Suppose that even when the entire cash reserves are carried into the last period, the available cash will fall short of the due amount $\bar{c}$ in one state, but that there will be enough cash to meet the minimum required "strategic" payment to avoid liquidation in that state. Under strategic play, it will be optimal to carry the reserves into the next period and then make the minimum required payment. Under non-strategic play, however, the reserves in excess of the minimum payment will also go to the debtholders until the payment of $\bar{c}$ is reached. Given this anticipated "overpayment," it will be optimal in some states for the equityholders to increase dividend payments and carry lower reserves with them into the last period. This decreases the payoffs to debtholders at maturity, increasing spreads.

To summarize, the impact of strategic debt service depends centrally on both equity issuance costs as well as the dividend policy in place: (a) Under residual dividends, strategic debt service

\footnotetext{
${ }^{9}$ This appears to conflict with Anderson and Sundaresan [3] who find that strategic debt-service is important in a model with prohibitively high equity-issuance costs. There are two reasons for this. First, Anderson and Sundaresan assume there are only fixed costs of liquidation; when these fixed costs are high, (7.2) is easier to meet. Second, there appears to be an implicit (and apparently inconsistent) assumption in their paper that at date $T$ alone, equityholders can liquidate the firm costlessly to meet debt service requirements. This means the term $f_{T}$ on the right-hand side of (7.1) is replaced with $V_{T}$, so (7.1) will always hold.
} 
always results in larger spreads than non-strategic debt service, but this is not true under optimal dividends, i.e., strategic debt service could lead to lower spreads than non-strategic debt service in this case; (b) In both cases, the relative importance of strategic debt service diminshes as equity costs rise; and (c) The quantitative impact may vary considerably across the two regimes with the impact on spreads under optimal dividends being substantially more or substantially less than under residual dividends.

\section{Comparison with a Merton Model}

As the third and final step in our analysis, we compare the spreads predicted by our model (i.e., Table 3) to the corresponding numbers obtained from an analog of the model in Merton [32]. The analogy will necessarily be imperfect, since ours is a cash-flow based model in which the treatment of intermediate cash flows plays a major role, while Merton's model has no intermediate cash flows. However, the spirit of Merton's model is implicitly one where all cash flows are used first for debt payment; that is, there is neither strategic debt-service nor an optimal dividend policy. Thus, a version of Merton's model may be reproduced in our framework by assuming that (a) no dividend payments occur until maturity of the debt, and (b) there is no strategic debt service. The first condition is identical to imposing a covenant on the firm that prohibits payment of any dividends till the debt is retired.

It is obvious intuitively - and easy to show formally - that our model will generate spreads that are higher than such a "modified-Merton" model. The only question therefore is the quantitative nature of the difference. This question is especially relevant given the inability of the Merton model to generate spreads of the size typically observed in practice.

Table 8 compares the spreads generated by the modified-Merton model to those from the optimal dividend model (Table 3). A glance at the table reveals that the optimal dividends model produces spreads that are at least 125 bps larger than the modified-Merton model; more typically, this difference exceeds 250 bps. Thus, the optimal dividends model's performance is more in line with observed evidence than the Merton model.

\section{Coupon Debt}

The path-dependence feature of optimal policies gets exacerbated by the presence of the interim debt-service requirements when we move from zero-coupon debt to coupon debt. The significant additional complexity this introduces into the model manifests itself in two ways. First, it is no longer possible to provide an analytical characterization of optimal dividend policies for coupon debt along the lines of Proposition 5.1 for zero-coupon debt. Second, the properties of equilibrium valuations themselves get affected in intricate ways.

To elaborate on this second point, consider, for definiteness, equilibrium debt valuations in the case where equity-issuance costs are positive. When debt has a zero-coupon structure, Proposition 5.4 established that 


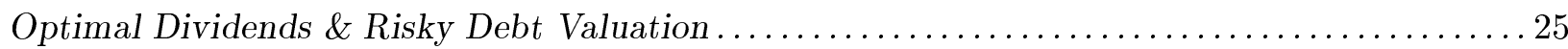

1. With zero liquidation costs, equilibrium debt values are identical under optimal and residual dividend policies.

2. With positive liquidation costs, equilibrium debt values are higher ${ }^{10}$ under optimal dividend policies than under residual dividend policies.

If the debt structure includes interim debt-service requirements, however, Proposition 9.1 below shows that each of these properties is non-trivially affected:

1. With zero liquidation costs, equilibrium debt values are lower (possibly strictly) under optimal dividend policies than under residual dividend policies.

2. With positive liquidation costs, equilibrium debt values under optimal dividend policies can be higher or lower than under residual dividend policies, depending on the size of liquidation costs and the debt structure in question.

Several aspects of these results are noteworthy. First, even with zero liquidation costs, optimal and residual dividend policies can now have markedly different implications. Second, it is now possible that optimal dividend policies lead to lower debt values (and therefore higher spreads) than residual dividend policies, which is impossible under any circumstances with zero-coupon debt. Third, with positive liquidation costs, the unambiguous relationship of Proposition 5.4 is replaced by ambiguity on the over/under-valuation issue. A complete statement of the result follows.

Proposition 9.1 Suppose the debt structure has some interim debt-service requirements.

1. If there are no equity-issuance costs, equilibrium debt and equity values are identical under optimal and residual dividend policies.

2. If equity-issuance costs are positive:

(a) If there are no liquidation costs, equity value is higher and debt value lower under an optimal dividend policy than under a residual dividend policy. (These inequalities can be strict.)

(b) If liquidation costs are non-zero, equity value is higher but debt value may be lower or higher under an optimal dividend policy than under a residual dividend policy.

Proof With zero equity-issuance costs, residual dividend policies are fully optimal as outlined in footnote 6 of Section 4, so assume equity-issuance costs are strictly positive. Now observe that, regardless of liquidation costs, equity value must always be higher under optimal dividend policies than residual dividend policies since equityholders cannot be worse off from having additional courses of action available to them. Thus, it remains to be shown that (a) with zero liquidation costs, debt values are lower under optimal dividend policies than residual dividend policies, and

\footnotetext{
${ }^{10}$ As earlier, the terms "higher" and "lower" always refer to the weak inequalities $\geq$ and $\leq$, respectively.
} 
(b) with positive liquidation costs, debt values can be either higher or lower under optimal dividend policies than under residual dividend policies.

To see (a), suppose there are no liquidation costs. In this case, the entire initial value $V_{0}$ of the firm is divided between equity value $V_{0}^{E}$ and debt value $V_{0}^{D}$, since expected future liquidation costs are zero at all points. If $V_{0}^{E}$ is higher (as it must be under optimal dividend policies), then $V_{0}^{D}$ must necessarily be lower. That these inequalities can be strict is shown in Example C.1 below. This establishes Part 2(a) of the proposition.

To see (b), consider first a given coupon structure which is such that under zero liquidation costs, equilibrium equity values are strictly higher and debt values strictly lower under optimal dividends than residual dividends. (The specification in Example C.1 is an instance.) A simple continuity argument establishes that if liquidation costs are positive but "small," these inequalities will continue to hold. Thus, there exist scenarios where with positive liquidation costs, equilibrium debt values are strictly lower under optimal dividends than under residual dividends establishing one part of the desired result.

To see the other part, consider a specification for which under zero-coupon debt, debt value is strictly higher under optimal dividends than residual dividends. (For instance, one of the specifications in Sections 6-7.) Another continuity argument shows that if a "small" interim coupon is appended to the debt-structure, the inequalities will continue to hold. Thus, it is also possible that with positive liquidation costs, equilibrium debt values could be strictly higher under optimal dividends than under residual dividends. This completes the proof of Proposition 9.1.

The driving forces behind Proposition 9.1 are easily described from an intuitive standpoint. As in Geske [17], coupon debt may be viewed as a compound option in the hands of equityholders in which (a) the payment of a coupon entitles the option-holder to proceed to the next coupon, and (b) the payment of the last-but-one coupon provides the equity holders with a call option to buy the firm from the debtholders at a strike price equal to the last payment due on the debt. Viewed in this light, the presence of coupons provides equityholders with additional options with which to effect a transfer of value from debt-holders to themselves. Moving from residual to optimal dividend policies enhances the equityholders' ability to exploit this optionality. As a consequence, debtholders may become worse off than under residual dividend policies. These intuitive arguments lie at the heart of our construction of Example C.1 and are made transparent there.

Proposition 9.1 further underscores the importance of assumptions concerning dividend policies in the presence of equity-issuance costs, and the mis-estimates that can result from ignoring the interplay of these factors. However, giving quantitative expression to these biases is much more difficult than was the case for Proposition 5.4: an analytical characterization of optimal dividend policies appears infeasible in the general case, and numerical estimation in the absence of such a characterization would involve the practically impossible task of searching over all possible dividend/debt-service policies. While this is unfortunate, it must be emphasized that the difficulty of working with coupon debt structures is not in itself new to our paper. Even in those models in the literature whose optimal strategies have the happy feature of path-independence, only the case of "continuous" coupons has proved tractable in general. 


\section{Conclusions}

This paper extends the models of Anderson and Sundaresan [3] and Mella-Barral and Perraudin [30] in two directions: (a) dividend policy is determined optimally rather than as the residual consequence of debt-service policy; and (b) the issuance of new equity is allowed to be a costly process. All the other attractive features of their approach — using a cash-flow based model of firm value, allowing for liquidation costs and strategic debt service- are retained.

We provide an analytical characterization of optimal policies in our model. Numerical analysis of the equilibrium then shows that the quantitative (and even qualitiative) predictions of the model depend in a central way on the two new features we introduce. In particular, we find that:

- Assuming dividends are determined residually, rather than optimally, can bias yield spreads predicted by the model upwards by as much as 200 basis points.

- The actual size of the bias depends crucially on equity-issuance costs. For small equityissuance costs the difference can be negligible, but it typically rises substantially as equityissuance costs rise.

- The marginal impact of strategic debt-service (a factor that has received much attention in the recent literature in this area) depends heavily on both equity-issuance costs and the dividend policy in place.

- In general, strategic debt-service only has a large effect on overall yield spreads when equity-issuance costs are low.

- Under residual dividend policies, strategic debt service always widens yield spreads. However, under optimal dividend policies, strategtic debt service widens yield spreads at low equity costs, but can actually narrow them at high equity costs.

In summary, our results indicate that ignoring the role of either of these two factors can result in substantial bias entering the model's predictions. 


\section{A The Binomial Cash Flow Process}

We show in this Appendix that if the cash flow process $\left\{\widetilde{f}_{t}\right\}$ follows a multiplicative binomial process, then the value process $V_{t}$ also follows a multiplicative binomial process. So suppose that given $f_{t}$, we have

$$
\widetilde{f}_{t+1}= \begin{cases}u f_{t}, & \text { with probability } p \\ d f_{t}, & \text { with probability } 1-p\end{cases}
$$

By definition, we have

$$
V_{t}=f_{t}+\beta E_{t}\left(V_{t+1}\right)
$$

Now note that since $\left\{\widetilde{f}_{t}\right\}$ is a stationary Markov process, so also is $\left\{V_{t}\right\}$. In particular, $V_{t}$ depends on the history of the cash flow process only through $f_{t}$. Thus, we can write (A.2) as

$$
\begin{aligned}
V\left(f_{t}\right) & =f_{t}+\beta E\left[V\left(\widetilde{f}_{t+1}\right)\right] \\
& =f_{t}+\beta\left[p V\left(u f_{t}\right)+(1-p) V\left(d f_{t}\right)\right]
\end{aligned}
$$

A standard argument using the Contraction Mapping Theorem shows that there can be one, and only one, bounded function $H(\cdot)$ such that

$$
H(f)=f+\beta[p H(u f)+(1-p) H(d f)], \quad f \in \mathbb{R}_{+} .
$$

Since $V(\cdot)$ satisfies (A.4) by definition, it follows that the fixed-point of $T$ must coincide with $V$, and, therefore, that $V$ is uniquely defined. On the other hand, a straightforward computation shows that the function $w$ defined by

$$
w(f)=\frac{f}{[1-\beta(p u+(1-p) d)]}, \quad f \in \mathbb{R}_{+}
$$

also satisfies (A.4). By uniqueness, we must have $V=w$. It is immediate from this and (A.1) that $V$ also follows a multiplicative binomial process.

\section{B Proofs}

\section{B.1 Proof of Proposition 5.1}

The proof uses a backwards induction argument.

Period $\boldsymbol{T}$ In the last period, the equilibrium evidently has the same structure as it does in the general case. Thus, given the cash reserves $\phi_{T}$ and the period- $T$ realized cash flow $f_{T}$, the equilibrium debt and equity values at $T$ are given by (4.2)-(4.5). 
Period $\boldsymbol{T}-1$ Given the cash reserves $\phi_{T-1}$ entering $T-1$ and the realized cash flow $f_{T-1}$ in that period, the owner-manager must decide on the dividend $\delta_{T-1}$ to be paid that period. (There is no debt-service amount to be considered.) For each choice of $\delta_{T-1}$, the period $-T$ cash reserves $\phi_{T}$ are determined as

$$
\phi_{T}=(1+\rho)\left(\phi_{T-1}+f_{T-1}-\delta_{T-1}\right) .
$$

The one-to-one relationship between $\delta_{T-1}$ and $\phi_{T}$ present in (B.6) implies that we could equivalently model the owner as picking $\phi_{T}$ directly, rather than $\delta_{T-1}$. This minor change of perspective turns out to simplify exposition considerably. Note that since $\delta_{T-1}$ must lie between 0 and $\left(\phi_{T-1}+f_{T-1}\right)$, the range of feasible values for $\phi_{T}$ is $\left[0, \phi_{T}^{\max }\right]$, where

$$
\phi_{T}^{\max }=(1+\rho)\left(\phi_{T-1}+f_{T-1}\right) .
$$

Pick any $\phi \in\left[0, \phi_{T}^{\max }\right]$. Let $E_{T-1}\left[V_{T}^{E}(\phi)\right]$ denote the expected continuation value of equity given $\phi$, where the expectation is conditional on all information available upto $T-1$ and is taken over possible realizations of period- $T$ cash flow $f_{T}$. Since the choice of $\phi$ implies a period- $(T-1)$ dividend of $\delta_{T-1}=\phi_{T-1}+f_{T-1}-\beta \phi$, the value of equity in period $T-1$ implied by the choice $\phi$ is

$$
\left(\phi_{T-1}+f_{T-1}-\beta \phi\right)+\beta E_{T-1}\left[V_{T}^{E}(\phi)\right]
$$

The owner-manager selects $\phi$ to maximize (B.8); the maximized value is the equilibrium value of equity in period $T-1$ :

$$
V_{T-1}^{E}=\max _{\phi \in\left[0, \phi_{T}^{\max }\right]}\left\{\left(\phi_{T-1}+f_{T-1}-\beta \phi\right)+\beta E_{T-1}\left[V_{T}^{E}(\phi)\right]\right\} .
$$

Period $\boldsymbol{T}-\mathbf{2}$ Let $\phi_{T-2}$ be the cash reserves entering period $T-2$, and let $f_{T-2}$ be the realized cash flows in that period. Define $\phi_{T-1}^{\max }=(1+\rho)\left(\phi_{T-2}+f_{T-2}\right)$. Analogous reasoning to that used in deriving the period $T-1$ equilibrium value establishes that in period $T-2$, the owner manager picks $\phi$ to solve

$$
V_{T-2}^{E}=\max _{\phi \in\left[0, \phi_{T-1}^{\max }\right]}\left\{\left(\phi_{T-2}+f_{T-2}-\beta \phi\right)+\beta E_{T-2}\left[V_{T-1}^{E}(\phi)\right]\right\}
$$

We will show that $\phi=\phi_{T-1}^{\max }$ solves this maximization problem. To this end, observe that the value of $V_{T-1}^{E}$ from (B.9) may be written as

$$
V_{T-1}^{E}=\phi_{T-1}+\max _{\phi \in\left[0, \phi_{T}^{\max }\right]}\left\{\left(f_{T-1}-\beta \phi\right)+\beta E_{T-1}\left[V_{T}^{E}(\phi)\right]\right\}
$$

Moreover, since the maximand on the right-hand side (the term in braces) does not depend on $\phi_{T-1}$, the maximization problem is affected by $\phi_{T-1}$ only through its effect on $\phi_{T}^{\max }$. Since $\phi_{T}^{\max }$ 
increases as $\phi_{T-1}$ increases, a larger value of $\phi_{T-1}$ implies a larger feasible set of actions, and, therefore, a (weakly) larger value of the maximized function. Putting all this together, it is seen that the time $T-1$ value of equity has the representation

$$
V_{T-1}^{E}=\phi_{T-1}+G\left(\phi_{T-1}\right)
$$

where $G(\cdot)$ is a non-decreasing function. We use this representation in (B.10). Substituting for $V_{T-1}^{E}$ from (B.12), we can write the time $T-2$ value of equity as

$$
V_{T-2}^{E}=\max _{\phi \in\left[0, \phi_{T-1}^{\max }\right]}\left\{\left(\phi_{T-2}+f_{T-2}-\beta \phi\right)+\beta E_{T-2}[\phi+G(\phi)]\right\}
$$

The term $\phi$ can clearly be pulled out of the expectation on the right-hand side. Doing so, and cancelling the common term $\beta \phi$ that results, this yields:

$$
V_{T-2}^{E}=\max _{\phi \in\left[0, \phi_{T-1}^{\max }\right]}\left\{\phi_{T-2}+f_{T-2}+\beta E_{T-2}[G(\phi)]\right\}
$$

Now, $G$, as we have already seen, is a non-decreasing function of $\phi$. Since the rest of the maximand is independent of $\phi$, it follows easily that one solution to (B.14) is to have $\phi=\phi_{T-1}^{\max }$, in particular, to pay no dividends at all in period $T-2$.

Period $\boldsymbol{t}<\boldsymbol{T}-\mathbf{2}$ An identical argument to that used for period $T-2$ establishes that it is an optimal policy in each preceding period to not pay any dividends, and instead to hold back the entire cash flow in the firm. This completes the proof of the proposition.

\section{B.2 Proof of Proposition 5.4}

Part 1 of the proposition is an immediate consequence of Corollary 5.3. We show part 2 here. Note that for equity values, this statement is obviously true: equity values cannot decrease when equity holders have additional alternatives available to them. To prove that debt values are also higher in this case, we use a backwards induction argument. Denote by $V_{t}^{D}\left(\phi_{t}\right)$ the time- $t$ value of debt in the model where dividends may be chosen optimally, given that cash reserves at the begining of period $t$ are $\phi_{t}$; and by $\bar{V}_{t}^{D}$ the corresponding quantity in the constrained model, where all excess cash is paid out as dividends. We will show that we must have $V_{t}^{D}\left(\phi_{t}\right) \geq \bar{V}_{t}^{D}$ for every $t$, which will obviously establish the desired result.

Let $D_{T}^{L}\left(\phi_{T}\right)$ denote the payoff to debt holders in the optimal-dividends model if liquidation were to occur at $T$ given the cash reserves $\phi_{T}$. Of course, $D_{T}^{L}(0)$ will be the liquidation payoff to debt holders at $T$ in the constrained model. Note that we must have $D_{T}^{L}\left(\phi_{T}\right) \geq D_{T}^{L}(0)$ for any $\phi_{T} \geq 0$.

Period $\boldsymbol{T}$ As we have seen above (expressions (4.2)-(4.5)), strategic debt-service by equity holders means that the equilibrium time- $T$ value of debt in the unconstrained model is given by the debtholders liquidation payoffs: $V_{T}^{D}\left(\phi_{T}\right)=D_{T}^{L}\left(\phi_{T}\right)$. A similar argument shows that in the constrained 
model also, the time $T$ value of debt is given by $\bar{V}_{T}^{D}=D_{T}^{L}(0)$. Of course, this means we must have $V_{T}^{D}\left(\phi_{T}\right) \geq \bar{V}_{T}^{D}$.

Period $\boldsymbol{T}-1$ Let $\phi_{T-1}$ denote the cash reserves at the begining of $T-1$. Given any dividend policy, let $\phi_{T} \geq 0$ denote the cash reserves that will exist at the begining of period $T$ in the optimal-dividends model. Then, we must have

$$
V_{T-1}^{D}\left(\phi_{T-1}\right)=\beta E_{T-1}\left[V_{T}^{D}\left(\phi_{T}\right)\right] \geq \beta E_{T-1}\left[\bar{V}_{T}^{D}\right]=\bar{V}_{T-1}^{D}
$$

Period $\boldsymbol{t}<\boldsymbol{T}-\mathbf{1}$ An easy backwards induction argument using (B.15) now establishes that $V_{t}^{D}\left(\phi_{t}\right) \geq \bar{V}_{t}^{D}$ for each $t$, completing the proof.

\section{Optimal Dividends in Coupon-Debt: An Example}

The following example illustrates that even with zero liquidation costs, the implications of optimal and residual dividend policies could differ if debt is of the coupon form; and, in particular, that residual dividend policies could substantially overestimate the value of debt in this case.

Example C.1 Consider a cash flow process specified by $f_{1}=f_{2}=f_{3}=1$,

$$
f_{4}=\left\{\begin{array}{rr}
160, & \text { with probability } 1 / 2 \\
80, & \text { with probability } 1 / 2
\end{array}\right.
$$

and $f_{t}=0$ for $t \geq 5$. To fix ideas, it may help to think of this as a project with a three-period gestation at the end of which it is marketed, and is either a success (resulting in a cash flow of 160) or a failure (a cash flow of 80). Letting $\beta=(1+\rho)^{-1}$ as usual, the present value of this project is

$$
V_{1}=1+\beta+\beta^{2}+\beta^{3}[(160+80) / 2] .
$$

Now consider a coupon-debt structure for this project, where a coupon payment of 2 is due in period 2, and a coupon of 2 and the principal face value of 100 are due in period 4 . In terms of our notation, we have:

$$
c_{2}=2, c_{4}=102, c_{t}=0 \text { for all } t \neq 2,4 \text {. }
$$

Next, we assume that if liquidation occurs in period $t$, the debt-holders are owed an amount equal to the coupon due in period $t$ plus the face value of the debt (this rule has been employed in practice). Thus, for the two periods where default may occur and the debt holders can force liquidation, we have $C_{2}=C_{4}=102$. Finally, we assume there are no liquidation costs: $L_{t}=0$ for all $t$; that new equity issuance is prohibitively expensive $(m(e)=e)$; and that the APR holds. 
Consider the residual dividends model first. We proceed by backwards induction. (a) At $t=4$, given zero liquidation costs, any underperformance on the debt contract will automatically trigger liquidation of the firm. Thus, debt holders receive either $\min \{160,102\}$ or $\min \{80,102\}$ depending on which state of the world occurs. (b) At $t=3$, there is no coupon due, so the cash flow of 1 is paid out as dividends. (c) At $t=2$, there is insufficient cash to meet the coupon payment of 2 . There are two alternatives facing the debt holders: (a) accept a payment of $\xi \leq 1$ and allow the firm to continue, or (b) liquidate the firm. In the former case, the value to the debt holders is

$$
\xi+\beta^{2}[(\min \{160,102\}+\min \{80,102\}) / 2]=\xi_{+} 91 \beta^{2} .
$$

If liquidation is chosen at this time, the value of the firm is $1+\beta+\beta^{2}[(160+80) / 2]=\left(1+\beta+120 \cdot \beta^{2}\right.$. Thus, the value to the debtholders from liquidation is

$$
\min \left\{1+\beta+120 \beta^{2}, 102\right\} .
$$

It is easily checked that the difference between (C.20) and (C.19) is strictly positive for all $\beta \in(0,1)$ and $\xi \in[0,1]$. It is immediate that debt holders will always choose liquidation in period 2 , so debt and equity values resolve as

$$
\begin{aligned}
& \bar{V}^{D}=\beta \min \left\{1+\beta+120 \beta^{2}, 102\right\} . \\
& \bar{V}^{E}=1+\beta \max \left\{0,1+\beta+120 \beta^{2}-102\right\},
\end{aligned}
$$

We turn now to the optimal dividends model. Carrying out the computations as above shows that the equilibrium strategy for equity holders is to receive no dividends in period 1 ; to receive all excess cash after paying the coupon as dividends in period 2; to receive a dividend of 1 in period 3 ; and to receive the residual amount (either $160-\min \{160,102\}$ or $80-\min \{80,102\}$ ) in period 4. The values of debt and equity under this strategy are easily seen to be

$$
\begin{aligned}
V^{D} & =\beta\left(2+91 \beta^{2}\right) . \\
V^{E} & =\beta\left(\rho+\beta+29 \beta^{2}\right) .
\end{aligned}
$$

Inspection of (C.21)-(C.24) makes it immediate that for all reasonable values of $\beta$, debt values are significantly higher, and equity values significantly lower, in the residual dividends model than in the optimal dividends model. For select values of $\rho$, numerical values of debt and equity and yield spreads predicted by either model are provided in Table 9.

The numbers in the table bear out the claim made above that ignoring the possibility of an optimal dividend policy under coupon debt could result in overvaluation of debt and a consequent underestimation of yield spreads. Indeed, the table shows that the differences in yield spreads may be very significant from a quantitative standpoint: in each case the spread under the optimal dividends model is substantially larger (by 300 bps or more) than the corresponding figure under residual dividends. 
Table 1: Equity and Debt values under Residual Dividend Policy

This table describes debt and equity values $\left(V^{D}\right.$ and $V^{D}$, respectively) and spreads of debt yields over the risk-free rate under residual dividend policies for the binomial cash flow model. Two parameters in the table are held fixed: the volatility $\sigma$ at $\sigma^{2}=0.10$, and the payout ratio $b$ at $b=0.025$. The remaining paremeters are as described in the table. $\bar{c}$ is the face-value of zero-coupon debt, $m_{0}$ and $m_{1}$ are the fixed and proportional costs of raising new equity, respectively, and $l_{0}$ and $l_{1}$ are the fixed and proportional costs of liquidation, respectively. $m_{0}$ is taken to be zero.

\begin{tabular}{||c|c|c|c|c||}
\hline \multicolumn{5}{|c||}{$l_{0}=0.0, l_{1}=0.25$} \\
\hline $\bar{c}$ & $m_{1}$ & $V^{E}$ & $V^{D}$ & Spread (bps) \\
\hline 0.25 & 0.00 & 0.868 & 0.132 & 128.3 \\
& 0.15 & 0.847 & 0.132 & 128.3 \\
& 0.99 & 0.727 & 0.132 & 128.3 \\
\hline 0.50 & 0.00 & 0.786 & 0.214 & 341.3 \\
& 0.15 & 0.751 & 0.214 & 341.3 \\
& 0.99 & 0.640 & 0.214 & 341.3 \\
\hline 0.75 & 0.00 & 0.732 & 0.268 & 530.1 \\
& 0.15 & 0.687 & 0.268 & 530.1 \\
& 0.99 & 0.586 & 0.268 & 530.1 \\
\hline
\end{tabular}

\begin{tabular}{||c|c|c|c|c||}
\hline \multicolumn{5}{||c||}{$l_{0}=0.1, l_{1}=0.25$} \\
\hline $\bar{c}$ & $m_{1}$ & $V^{E}$ & $V^{D}$ & Spread (bps) \\
\hline 0.25 & 0.00 & 0.889 & 0.111 & 303.8 \\
& 0.15 & 0.872 & 0.111 & 303.8 \\
& 0.99 & 0.697 & 0.111 & 303.8 \\
\hline 0.50 & 0.00 & 0.817 & 0.183 & 505.6 \\
& 0.15 & 0.787 & 0.183 & 505.6 \\
& 0.99 & 0.620 & 0.183 & 505.6 \\
\hline 0.75 & 0.00 & 0.773 & 0.227 & 705.9 \\
& 0.15 & 0.736 & 0.227 & 705.9 \\
& 0.99 & 0.575 & 0.227 & 705.9 \\
\hline
\end{tabular}

\begin{tabular}{||c|c|c|c|c||}
\hline \multicolumn{5}{|c||}{$l_{0}=0.2, l_{1}=0.25$} \\
\hline $\bar{c}$ & $m_{1}$ & $V^{E}$ & $V^{D}$ & Spread (bps) \\
\hline 0.25 & 0.00 & 0.909 & 0.091 & 506.5 \\
& 0.15 & 0.895 & 0.091 & 506.5 \\
& 0.99 & 0.680 & 0.091 & 506.5 \\
\hline 0.50 & 0.00 & 0.850 & 0.150 & 714.6 \\
& 0.15 & 0.826 & 0.150 & 714.6 \\
& 0.99 & 0.616 & 0.150 & 714.6 \\
\hline 0.75 & 0.00 & 0.807 & 0.193 & 878.2 \\
& 0.15 & 0.775 & 0.193 & 878.2 \\
& 0.99 & 0.572 & 0.193 & 878.2 \\
\hline
\end{tabular}


Table 2: Equity and Debt values under Residual Dividend Policy

This table describes debt and equity values ( $V^{D}$ and $V^{E}$, respectively) and spreads of debt yields over the risk-free rate under residual dividend policies for the binomial cash flow model. Fixed and proportional costs of liquidation are held fixed at $l_{0}=0.1$ and $l_{1}=0.25$, respectively, and $\bar{c}$, the face-value of zero-coupon debt is fixed at 0.50. Volatility is held fixed in the first panel at $\sigma^{2}=0.10$ and the payout ratio, $b$ is held fixed in the second panel at $b=0.025 . m_{0}$ and $m_{1}$ are the fixed and proportional costs of raising new equity, respectively. $m_{0}$ is taken to be zero.

\begin{tabular}{||c|c|c|c|c||}
\hline \multicolumn{5}{|c||}{ Effect of varying payout ratio $b$} \\
\hline$m_{1}$ & $b$ & $V^{E}$ & $V^{D}$ & Spread (bps) \\
\hline 0.00 & 0.015 & 0.795 & 0.205 & 387.4 \\
& 0.025 & 0.817 & 0.183 & 505.6 \\
& 0.035 & 0.840 & 0.160 & 649.4 \\
\hline 0.10 & 0.015 & 0.774 & 0.205 & 387.4 \\
& 0.025 & 0.798 & 0.183 & 505.6 \\
& 0.035 & 0.825 & 0.160 & 649.4 \\
\hline 0.15 & 0.015 & 0.761 & 0.205 & 387.4 \\
& 0.025 & 0.787 & 0.183 & 505.6 \\
& 0.035 & 0.815 & 0.160 & 649.4 \\
\hline 0.99 & 0.015 & 0.559 & 0.205 & 387.4 \\
& 0.025 & 0.620 & 0.183 & 505.6 \\
& 0.035 & 0.675 & 0.160 & 649.4 \\
\hline
\end{tabular}

\begin{tabular}{||c|c|c|c|c||}
\hline \multicolumn{5}{|c||}{ Effect of varying volatility $\sigma$} \\
\hline$m_{1}$ & $\sigma^{2}$ & $V^{E}$ & $V^{D}$ & Spread (bps) \\
\hline 0.00 & 0.03 & 0.755 & 0.245 & 202.2 \\
& 0.10 & 0.817 & 0.183 & 505.6 \\
& 0.20 & 0.868 & 0.132 & 853.8 \\
\hline 0.10 & 0.03 & 0.729 & 0.245 & 202.2 \\
& 0.10 & 0.798 & 0.183 & 505.6 \\
& 0.20 & 0.855 & 0.132 & 853.8 \\
\hline 0.15 & 0.03 & 0.714 & 0.245 & 202.2 \\
& 0.10 & 0.787 & 0.183 & 505.6 \\
& 0.20 & 0.847 & 0.132 & 853.8 \\
\hline 0.99 & 0.03 & 0.548 & 0.245 & 202.2 \\
& 0.10 & 0.620 & 0.183 & 505.6 \\
& 0.20 & 0.691 & 0.132 & 853.8 \\
\hline
\end{tabular}


Table 3: Equity and Debt values under Optimal Dividend Policy

This table describes debt and equity values ( $V^{D}$ and $V^{D}$, respectively) and spreads of debt yields over the risk-free rate under residual dividend policies for the binomial cash flow model. Two parameters in the table are held fixed: the volatility $\sigma$ at $\sigma^{2}=0.10$, and the payout ratio $b$ at $b=0.025$. The remaining paremeters are as described in the table. $\bar{c}$ is the face-value of zero-coupon debt, $m_{0}$ and $m_{1}$ are the fixed and proportional costs of raising new equity, respectively, and $l_{0}$ and $l_{1}$ are the fixed and proportional costs of liquidation, respectively. $m_{0}$ is taken to be zero.

\begin{tabular}{||c|c|c|c|c||}
\hline \multicolumn{5}{|c||}{$l_{0}=0.0, l_{1}=0.25$} \\
\hline $\bar{c}$ & $m_{1}$ & $V^{E}$ & $V^{D}$ & Spread (bps) \\
\hline 0.25 & 0.00 & 0.868 & 0.132 & 128.3 \\
& 0.15 & 0.864 & 0.132 & 125.5 \\
& 0.99 & 0.861 & 0.137 & 93.0 \\
\hline 0.50 & 0.00 & 0.786 & 0.214 & 341.3 \\
& 0.15 & 0.769 & 0.220 & 312.9 \\
& 0.99 & 0.757 & 0.219 & 316.2 \\
\hline 0.75 & 0.00 & 0.732 & 0.268 & 530.1 \\
& 0.15 & 0.705 & 0.274 & 505.8 \\
& 0.99 & 0.675 & 0.272 & 515.4 \\
\hline
\end{tabular}

\begin{tabular}{||c|c|c|c|c||}
\hline \multicolumn{5}{||c||}{$l_{0}=0.1, l_{1}=0.25$} \\
\hline $\bar{c}$ & $m_{1}$ & $V^{E}$ & $V^{D}$ & Spread (bps) \\
\hline 0.25 & 0.00 & 0.889 & 0.111 & 303.8 \\
& 0.15 & 0.884 & 0.111 & 303.8 \\
& 0.99 & 0.868 & 0.128 & 154.6 \\
\hline 0.50 & 0.00 & 0.817 & 0.183 & 505.6 \\
& 0.15 & 0.805 & 0.183 & 505.2 \\
& 0.99 & 0.762 & 0.193 & 450.6 \\
\hline 0.75 & 0.00 & 0.773 & 0.227 & 705.9 \\
& 0.15 & 0.752 & 0.227 & 705.9 \\
& 0.99 & 0.679 & 0.233 & 676.8 \\
\hline
\end{tabular}

\begin{tabular}{||c|c|c|c|c||}
\hline \multicolumn{5}{||c||}{$l_{0}=0.2, l_{1}=0.25$} \\
\hline $\bar{c}$ & $m_{1}$ & $V^{E}$ & $V^{D}$ & Spread (bps) \\
\hline 0.25 & 0.00 & 0.909 & 0.091 & 506.5 \\
& 0.15 & 0.903 & 0.091 & 506.5 \\
& 0.99 & 0.885 & 0.115 & 270.8 \\
\hline 0.50 & 0.00 & 0.850 & 0.150 & 714.6 \\
& 0.15 & 0.838 & 0.155 & 678.5 \\
& 0.99 & 0.782 & 0.190 & 467.0 \\
\hline 0.75 & 0.00 & 0.807 & 0.193 & 878.2 \\
& 0.15 & 0.791 & 0.194 & 876.0 \\
& 0.99 & 0.696 & 0.220 & 741.2 \\
\hline
\end{tabular}


Table 4: Equity and Debt values under Optimal Dividend Policy

This table describes debt and equity values ( $V^{D}$ and $V^{E}$, respectively) and spreads of debt yields over the risk-free rate under residual dividend policies for the binomial cash flow model. Fixed and proportional costs of liquidation are held fixed at $l_{0}=0.1$ and $l_{1}=0.25$, respectively, and $\bar{c}$, the face-value of zero-coupon debt is fixed at 0.50. Volatility is held fixed in the first panel at $\sigma^{2}=0.10$ and the payout ratio, $b$ is held fixed in the second panel at $b=0.025 . m_{0}$ and $m_{1}$ are the fixed and proportional costs of raising new equity, respectively. $m_{0}$ is taken to be zero.

\begin{tabular}{||c|c|c|c|c||}
\hline \multicolumn{5}{|c||}{ Effect of varying payout ratio $b$} \\
\hline$m_{1}$ & $b$ & $V^{E}$ & $V^{D}$ & Spread (bps) \\
\hline 0.00 & 0.015 & 0.795 & 0.205 & 387.4 \\
& 0.025 & 0.817 & 0.183 & 505.6 \\
& 0.035 & 0.840 & 0.160 & 649.4 \\
\hline 0.10 & 0.015 & 0.787 & 0.205 & 387.2 \\
& 0.025 & 0.810 & 0.183 & 505.2 \\
& 0.035 & 0.833 & 0.160 & 648.7 \\
\hline 0.15 & 0.015 & 0.782 & 0.205 & 387.2 \\
& 0.025 & 0.805 & 0.183 & 505.2 \\
& 0.035 & 0.829 & 0.160 & 648.7 \\
\hline 0.99 & 0.015 & 0.699 & 0.206 & 379.0 \\
& 0.025 & 0.762 & 0.193 & 450.6 \\
& 0.035 & 0.787 & 0.173 & 566.6 \\
\hline
\end{tabular}

\begin{tabular}{||c|c|c|c|c||}
\hline \multicolumn{5}{|c||}{ Effect of varying volatility $\sigma$} \\
\hline$m_{1}$ & $\sigma^{2}$ & $V^{E}$ & $V^{D}$ & Spread (bps) \\
\hline 0.00 & 0.03 & 0.755 & 0.245 & 202.2 \\
& 0.10 & 0.817 & 0.183 & 505.6 \\
& 0.20 & 0.868 & 0.132 & 853.8 \\
\hline 0.10 & 0.03 & 0.744 & 0.250 & 183.5 \\
& 0.10 & 0.810 & 0.183 & 505.2 \\
& 0.20 & 0.861 & 0.134 & 832.7 \\
\hline 0.15 & 0.03 & 0.740 & 0.250 & 183.5 \\
& 0.10 & 0.805 & 0.183 & 505.2 \\
& 0.20 & 0.858 & 0.134 & 832.6 \\
\hline 0.99 & 0.03 & 0.710 & 0.261 & 140.3 \\
& 0.10 & 0.762 & 0.193 & 450.6 \\
& 0.20 & 0.816 & 0.148 & 732.9 \\
\hline
\end{tabular}


Table 5: Comparison of Optimal and Residual Dividend Policies

This table describes the differences in debt and equity values ( $V^{D}$ and $V^{E}$, respectively) and in spreads of debt yields over the risk-free rate between the optimal and residual dividends models. The parameter values are the same as in Tables 1 and 3. The volatility $\sigma$ is held fixed at $\sigma^{2}=0.10$, and the payout ratio $b$ is fixed at $b=0.025$. The remaining parameters are as described in the table. $\bar{c}$ is the face-value of zero-coupon debt, $m_{0}$ and $m_{1}$ are the fixed and proportional costs of raising new equity, respectively, and $l_{0}$ and $l_{1}$ are the fixed and proportional costs of liquidation, respectively. $m_{0}$ is taken to be zero.

\begin{tabular}{||c|c|c|c|c||}
\hline \multicolumn{5}{||c||}{$l_{0}=0.0, l_{1}=0.25$} \\
\hline $\bar{c}$ & $m_{1}$ & Diff. in $V^{E}$ & Diff. in $V^{D}$ & Diff. in Spread (bps) \\
\hline 0.25 & 0.00 & 0.0000 & 0.0000 & 0.00 \\
& 0.15 & 0.0163 & 0.0004 & 2.86 \\
& 0.99 & 0.1331 & 0.0047 & 35.32 \\
\hline 0.50 & 0.00 & 0.0000 & 0.0000 & 0.00 \\
& 0.15 & 0.0187 & 0.0060 & 28.42 \\
& 0.99 & 0.1169 & 0.0053 & 25.13 \\
\hline 0.75 & 0.00 & 0.0000 & 0.0000 & 0.00 \\
& 0.15 & 0.0179 & 0.0063 & 24.33 \\
& 0.99 & 0.0897 & 0.0038 & 14.68 \\
\hline
\end{tabular}

\begin{tabular}{||c|c|c|c|c||}
\hline \multicolumn{5}{||c||}{$l_{0}=0.1, l_{1}=0.25$} \\
\hline $\bar{c}$ & $m_{1}$ & Diff. in $V^{E}$ & Diff. in $V^{D}$ & Diff. in Spread (bps) \\
\hline 0.25 & 0.00 & 0.0000 & 0.0000 & 0.00 \\
& 0.15 & 0.0125 & 0.0000 & 0.00 \\
& 0.99 & 0.1713 & 0.0174 & 149.15 \\
\hline 0.50 & 0.00 & 0.0000 & 0.0000 & 0.00 \\
& 0.15 & 0.0180 & 0.0001 & 0.35 \\
& 0.99 & 0.1424 & 0.0099 & 54.98 \\
\hline 0.75 & 0.00 & 0.0000 & 0.0000 & 0.00 \\
& 0.15 & 0.0161 & 0.0000 & 0.00 \\
& 0.99 & 0.1037 & 0.0063 & 29.13 \\
\hline
\end{tabular}

\begin{tabular}{||c|c|c|c|c||}
\hline \multicolumn{5}{||c||}{$l_{0}=0.2, l_{1}=0.25$} \\
\hline $\bar{c}$ & $m_{1}$ & Diff. in $V^{E}$ & Diff. in $V^{D}$ & Diff. in Spread (bps) \\
\hline 0.25 & 0.00 & 0.0000 & 0.0000 & 0.00 \\
& 0.15 & 0.0081 & 0.0000 & 0.00 \\
& 0.99 & 0.2056 & 0.0233 & 235.67 \\
\hline 0.50 & 0.00 & 0.0000 & 0.0000 & 0.00 \\
& 0.15 & 0.0120 & 0.0052 & 36.17 \\
& 0.99 & 0.1667 & 0.0396 & 247.63 \\
\hline 0.75 & 0.00 & 0.0000 & 0.0000 & 0.00 \\
& 0.15 & 0.0157 & 0.0004 & 2.20 \\
& 0.99 & 0.1242 & 0.0262 & 137.06 \\
\hline
\end{tabular}


Table 6: Residual Dividend Policy without Strategic Debt service

This table describes the difference in debt and equity values $\left(V^{D}\right.$ and $V^{E}$, respectively) and spreads of debt yields over the risk-free rate under residual dividend policies for the binomial cash flow model when debt service is strategic and non-strategic. The parameter combinations are the same as in Table 1. The volatility $\sigma$ is held fixed at $\sigma^{2}=0.10$, and the payout ratio $b$ is fixed at $b=0.025$. The remaining parameters are as described in the table. $\bar{c}$ is the face-value of zero-coupon debt, $m_{0}$ and $m_{1}$ are the fixed and proportional costs of raising new equity, respectively, and $l_{0}$ and $l_{1}$ are the fixed and proportional costs of liquidation, respectively. $m_{0}$ is taken to be zero.

\begin{tabular}{||c|c|c|c|c|c|c|c||}
\hline \multicolumn{1}{||c|}{$l_{0}=0.0, l_{1}=0.25$} \\
\hline $\bar{c}$ & $m_{1}$ & $V^{E}$ & $V^{D}$ & Spread (bps) & Diff. in $V^{E}$ & Diff. in $V^{D}$ & Diff. in Spread (bps) \\
\hline 0.25 & 0.00 & 0.862 & 0.132 & 123.7 & 0.0057 & -0.0006 & 4.61 \\
& 0.15 & 0.844 & 0.132 & 123.7 & 0.0032 & -0.0006 & 4.61 \\
& 0.99 & 0.443 & 0.132 & 128.3 & 0.2844 & 0.0000 & 0.00 \\
\hline 0.50 & 0.00 & 0.761 & 0.226 & 284.2 & 0.0247 & -0.0122 & 57.17 \\
& 0.15 & 0.738 & 0.214 & 341.3 & 0.0125 & 0.0000 & 0.00 \\
& 0.99 & 0.419 & 0.214 & 341.3 & 0.2207 & 0.0000 & 0.00 \\
\hline 0.75 & 0.00 & 0.692 & 0.283 & 473.6 & 0.0404 & -0.0148 & 56.51 \\
& 0.15 & 0.665 & 0.268 & 530.1 & 0.0221 & 0.0000 & 0.00 \\
& 0.99 & 0.414 & 0.268 & 530.1 & 0.1713 & 0.0000 & 0.00 \\
\hline
\end{tabular}

\begin{tabular}{||c|c|c|c|c|c|c|c||}
\hline \multicolumn{1}{||c|}{$l_{0}=0.1, l_{1}=0.25$} \\
\hline $\bar{c}$ & $m_{1}$ & $V^{E}$ & $V^{D}$ & Spread (bps) & Diff. in $V^{E}$ & Diff. in $V^{D}$ & Diff. in Spread (bps) \\
\hline 0.25 & 0.00 & 0.869 & 0.121 & 217.0 & 0.0197 & -0.0098 & 86.79 \\
& 0.15 & 0.851 & 0.121 & 217.0 & 0.0208 & -0.0098 & 86.79 \\
& 0.99 & 0.450 & 0.111 & 302.2 & 0.2469 & -0.0002 & 1.63 \\
\hline 0.50 & 0.00 & 0.768 & 0.206 & 382.9 & 0.0491 & -0.0228 & 122.73 \\
& 0.15 & 0.745 & 0.183 & 503.9 & 0.0424 & -0.0003 & 1.68 \\
& 0.99 & 0.426 & 0.183 & 504.6 & 0.1936 & -0.0002 & 1.01 \\
\hline 0.75 & 0.00 & 0.699 & 0.252 & 595.6 & 0.0746 & -0.0248 & 110.31 \\
& 0.15 & 0.672 & 0.227 & 705.1 & 0.0634 & -0.0002 & 0.83 \\
& 0.99 & 0.421 & 0.227 & 705.1 & 0.1539 & -0.0002 & 0.83 \\
\hline
\end{tabular}

\begin{tabular}{||c|c|c|c|c|c|c|c||}
\hline \multicolumn{1}{||c|}{$l_{0}=0.2, l_{1}=0.25$} \\
\hline $\bar{c}$ & $m_{1}$ & $V^{E}$ & $V^{D}$ & Spread (bps) & Diff. in $V^{E}$ & Diff. in $V^{D}$ & Diff. in Spread (bps) \\
\hline 0.25 & 0.00 & 0.882 & 0.118 & 244.9 & 0.0262 & -0.0262 & 261.54 \\
& 0.15 & 0.864 & 0.118 & 244.9 & 0.0308 & -0.0262 & 261.54 \\
& 0.99 & 0.463 & 0.092 & 500.6 & 0.2167 & -0.0005 & 5.87 \\
\hline 0.50 & 0.00 & 0.781 & 0.193 & 446.9 & 0.0687 & -0.0433 & 267.74 \\
& 0.15 & 0.758 & 0.160 & 643.0 & 0.0678 & -0.0104 & 71.67 \\
& 0.99 & 0.439 & 0.151 & 711.0 & 0.1763 & -0.0005 & 3.64 \\
\hline 0.75 & 0.00 & 0.712 & 0.229 & 695.5 & 0.0950 & -0.0358 & 182.73 \\
& 0.15 & 0.685 & 0.195 & 870.8 & 0.0897 & -0.0013 & 7.48 \\
& 0.99 & 0.434 & 0.194 & 875.4 & 0.1374 & -0.0005 & 2.87 \\
\hline
\end{tabular}


Table 7: Optimal Dividend Policy without Strategic Debt service

This table describes the difference in debt and equity values $\left(V^{D}\right.$ and $V^{E}$, respectively) and spreads of debt yields over the risk-free rate under optimal dividend policies for the binomial cash flow model when debt service is strategic and non-strategic. The parameter combinations are the same as in Table 3. The volatility $\sigma$ is held fixed at $\sigma^{2}=0.10$, and the payout ratio $b$ is fixed at $b=0.025$. The remaining parameters are as described in the table. $\bar{c}$ is the face-value of zero-coupon debt, $m_{0}$ and $m_{1}$ are the fixed and proportional costs of raising new equity, respectively, and $l_{0}$ and $l_{1}$ are the fixed and proportional costs of liquidation, respectively. $m_{0}$ is taken to be zero.

\begin{tabular}{||c|c|c|c|c|c|c|c||}
\hline \multicolumn{9}{||c||}{$l_{0}=0.0, l_{1}=0.25$} \\
\hline $\bar{c}$ & $m_{1}$ & $V^{E}$ & $V^{D}$ & Spread (bps) & Diff. in $V^{E}$ & Diff. in $V^{D}$ & Diff. in Spread (bps) \\
\hline 0.25 & 0.00 & 0.862 & 0.132 & 123.7 & 0.0057 & -0.0006 & 4.61 \\
& 0.15 & 0.861 & 0.132 & 123.7 & 0.0028 & -0.0002 & 1.75 \\
& 0.99 & 0.861 & 0.137 & 93.0 & 0.0000 & 0.0000 & 0.00 \\
\hline 0.50 & 0.00 & 0.761 & 0.226 & 284.2 & 0.0247 & -0.0122 & 57.17 \\
& 0.15 & 0.760 & 0.221 & 308.2 & 0.0090 & -0.0010 & 4.67 \\
& 0.99 & 0.754 & 0.219 & 316.1 & 0.0028 & -0.0000 & 0.06 \\
\hline 0.75 & 0.00 & 0.692 & 0.283 & 473.6 & 0.0404 & -0.0148 & 56.51 \\
& 0.15 & 0.688 & 0.276 & 500.1 & 0.0173 & -0.0015 & 5.69 \\
& 0.99 & 0.664 & 0.272 & 515.4 & 0.0110 & -0.0000 & 0.07 \\
\hline
\end{tabular}

\begin{tabular}{||c|c|c|c|c|c|c|c||}
\hline \multicolumn{1}{||c|}{$l_{0}=0.1, l_{1}=0.25$} \\
\hline $\bar{c}$ & $m_{1}$ & $V^{E}$ & $V^{D}$ & Spread (bps) & Diff. in $V^{E}$ & Diff. in $V^{D}$ & Diff. in Spread (bps) \\
\hline 0.25 & 0.00 & 0.869 & 0.121 & 217.0 & 0.0197 & -0.0098 & 86.79 \\
& 0.15 & 0.868 & 0.121 & 217.0 & 0.0166 & -0.0098 & 86.79 \\
& 0.99 & 0.868 & 0.129 & 149.7 & 0.0006 & -0.0006 & 4.97 \\
\hline 0.50 & 0.00 & 0.768 & 0.206 & 382.9 & 0.0491 & -0.0228 & 122.73 \\
& 0.15 & 0.767 & 0.196 & 432.9 & 0.0381 & -0.0131 & 72.37 \\
& 0.99 & 0.761 & 0.193 & 449.7 & 0.0012 & -0.0002 & 0.95 \\
\hline 0.75 & 0.00 & 0.699 & 0.252 & 595.6 & 0.0746 & -0.0248 & 110.31 \\
& 0.15 & 0.695 & 0.240 & 646.2 & 0.0569 & -0.0131 & 59.71 \\
& 0.99 & 0.671 & 0.233 & 675.9 & 0.0076 & -0.0002 & 0.87 \\
\hline
\end{tabular}

\begin{tabular}{||c|c|c|c|c|c|c|c||}
\hline \multicolumn{1}{||c|}{$l_{0}=0.2, l_{1}=0.25$} \\
\hline $\bar{c}$ & $m_{1}$ & $V^{E}$ & $V^{D}$ & Spread (bps) & Diff. in $V^{E}$ & Diff. in $V^{D}$ & Diff. in Spread (bps) \\
\hline 0.25 & 0.00 & 0.882 & 0.118 & 244.9 & 0.0262 & -0.0262 & 261.54 \\
& 0.15 & 0.881 & 0.118 & 244.9 & 0.0222 & -0.0262 & 261.54 \\
& 0.99 & 0.880 & 0.110 & 311.2 & 0.0052 & 0.0044 & -40.45 \\
\hline 0.50 & 0.00 & 0.791 & 0.199 & 415.5 & 0.0589 & -0.0493 & 299.15 \\
& 0.15 & 0.788 & 0.199 & 415.5 & 0.0500 & -0.0441 & 262.98 \\
& 0.99 & 0.778 & 0.184 & 499.3 & 0.0046 & 0.0058 & -32.33 \\
\hline 0.75 & 0.00 & 0.715 & 0.240 & 647.4 & 0.0915 & -0.0464 & 230.89 \\
& 0.15 & 0.712 & 0.223 & 722.9 & 0.0792 & -0.0296 & 153.11 \\
& 0.99 & 0.688 & 0.214 & 769.7 & 0.0081 & 0.0058 & -28.55 \\
\hline
\end{tabular}


Table 8: Modified Merton model and its comparison with Optimal Dividend Policy

This table describes debt and equity values ( $V^{D}$ and $V^{E}$, respectively) and spreads of debt yields over the risk-free rate under the modified-Merton model; and the differences betweeen these numbers and the corresponding ones in the optimal dividends model (Table 3). The parameter values are the same as in Table 3. Two parameters in the table are held fixed: the volatility $\sigma$ at $\sigma^{2}=0.10$, and the payout ratio $b$ at $b=0.025$. The remaining paremeters are as described in the table. $\bar{c}$ is the face-value of zero-coupon debt, $m_{0}$ and $m_{1}$ are the fixed and proportional costs of raising new equity, respectively, and $l_{0}$ and $l_{1}$ are the fixed and proportional costs of liquidation, respectively. $m_{0}$ is taken to be zero.

\begin{tabular}{||c|c|c|c|c|c|c|c||}
\hline \multicolumn{9}{||c||}{$l_{0}=0.0, l_{1}=0.25$} \\
\hline $\bar{c}$ & $m_{1}$ & $V^{E}$ & $V^{D}$ & Spread (bps) & Diff. in $V^{E}$ & Diff. in $V^{D}$ & Diff. in Spread (bps) \\
\hline 0.25 & 0.00 & 0.851 & 0.149 & 1.90 & 0.0177 & -0.0177 & 126.43 \\
& 0.15 & 0.850 & 0.149 & 1.90 & 0.0132 & -0.0173 & 123.57 \\
& 0.99 & 0.850 & 0.149 & 1.90 & 0.0107 & -0.0130 & 91.12 \\
\hline 0.50 & 0.00 & 0.715 & 0.285 & 51.7 & 0.0704 & -0.0704 & 289.62 \\
& 0.15 & 0.713 & 0.285 & 51.7 & 0.0561 & -0.0644 & 261.20 \\
& 0.99 & 0.682 & 0.285 & 51.7 & 0.0745 & -0.0651 & 264.48 \\
\hline 0.75 & 0.00 & 0.612 & 0.388 & 148.8 & 0.1197 & -0.1197 & 381.37 \\
& 0.15 & 0.604 & 0.388 & 148.8 & 0.1009 & -0.1135 & 357.04 \\
& 0.99 & 0.523 & 0.388 & 148.8 & 0.1525 & -0.1160 & 366.69 \\
\hline
\end{tabular}

\begin{tabular}{||c|c|c|c|c|c|c|c||}
\hline \multicolumn{1}{||c|}{$l_{0}=0.1, l_{1}=0.25$} \\
\hline $\bar{c}$ & $m_{1}$ & $V^{E}$ & $V^{D}$ & Spread (bps) & Diff. in $V^{E}$ & Diff. in $V^{D}$ & Diff. in Spread (bps) \\
\hline 0.25 & 0.00 & 0.853 & 0.147 & 18.8 & 0.0360 & -0.0360 & 284.98 \\
& 0.15 & 0.853 & 0.147 & 18.8 & 0.0314 & -0.0360 & 284.98 \\
& 0.99 & 0.853 & 0.147 & 18.8 & 0.0152 & -0.0185 & 135.83 \\
\hline 0.50 & 0.00 & 0.730 & 0.270 & 106.0 & 0.0868 & -0.0868 & 399.62 \\
& 0.15 & 0.729 & 0.270 & 106.0 & 0.0761 & -0.0867 & 399.27 \\
& 0.99 & 0.697 & 0.270 & 106.0 & 0.0651 & -0.0769 & 344.64 \\
\hline 0.75 & 0.00 & 0.639 & 0.361 & 222.2 & 0.1337 & -0.1337 & 483.73 \\
& 0.15 & 0.634 & 0.361 & 222.2 & 0.1174 & -0.1337 & 483.73 \\
& 0.99 & 0.543 & 0.361 & 222.2 & 0.1361 & -0.1275 & 454.60 \\
\hline
\end{tabular}

\begin{tabular}{||c|c|c|c|c|c|c|c||}
\hline \multicolumn{1}{||c|}{$l^{2}$} & \multicolumn{7}{c||}{$l_{0}=0.2, l_{1}=0.25$} \\
\hline $\bar{c}$ & $m_{1}$ & $V^{E}$ & $V^{D}$ & Spread (bps) & Diff. in $V^{E}$ & Diff. in $V^{D}$ & Diff. in Spread (bps) \\
\hline 0.25 & 0.00 & 0.860 & 0.140 & 66.8 & 0.0488 & -0.0488 & 439.68 \\
& 0.15 & 0.860 & 0.140 & 66.8 & 0.0433 & -0.0488 & 439.68 \\
& 0.99 & 0.860 & 0.140 & 66.8 & 0.0255 & -0.0255 & 204.01 \\
\hline 0.50 & 0.00 & 0.750 & 0.250 & 183.6 & 0.0997 & -0.0997 & 531.04 \\
& 0.15 & 0.750 & 0.250 & 183.6 & 0.0882 & -0.0945 & 494.87 \\
& 0.99 & 0.726 & 0.250 & 183.6 & 0.0558 & -0.0600 & 283.41 \\
\hline 0.75 & 0.00 & 0.670 & 0.330 & 312.6 & 0.1369 & -0.1369 & 565.67 \\
& 0.15 & 0.667 & 0.330 & 312.6 & 0.1241 & -0.1365 & 563.47 \\
& 0.99 & 0.577 & 0.330 & 312.6 & 0.1186 & -0.1107 & 428.61 \\
\hline
\end{tabular}


Table 9: Impact of Strategic Dividend Policy on Valuations

This table describes equilibrium valuations of equity and debt for the model of Appendix $\mathrm{C}$ under two the residual dividend and optimal dividend regimes. The table also describes equilibrium spreads (over the default-free rate) under the two models. Three values are used for the default-free interest rate $\rho$. The remaining parameter values are as stated in the Example. The terms $V^{D}$ and $V^{E}$ refer, respectively, to the values of debt and equity in equilibrium.

\begin{tabular}{||l|c|c|c||}
\hline \multicolumn{4}{|c||}{$\rho=0.000$} \\
\hline Model & $V^{D}$ & $V^{E}$ & Spread (in bps) \\
\hline Residual Dividends & 102.00 & 21.00 & 66 \\
\hline Optimal Dividends & 93.00 & 30.00 & 385 \\
\hline
\end{tabular}

\begin{tabular}{||l|c|c|c||}
\hline \multicolumn{4}{|c||}{$\rho=0.005$} \\
\hline Model & $V^{D}$ & $V^{E}$ & Spread (in bps) \\
\hline Residual Dividends & 101.49 & 19.71 & 83 \\
\hline Optimal Dividends & 91.64 & 29.56 & 387 \\
\hline
\end{tabular}

\begin{tabular}{||l|c|c|c||}
\hline \multicolumn{4}{|c||}{$\rho=0.010$} \\
\hline Model & $V^{D}$ & $V^{E}$ & Spread (in bps) \\
\hline Residual Dividends & 100.99 & 18.45 & 0 \\
\hline Optimal Dividends & 90.28 & 29.16 & 389 \\
\hline
\end{tabular}


Optimal Dividends \& Risky Debt Valuation

.42

\section{References}

[1] Alderson, M. and B. Betker (1995) Liquidation Costs and Capital Structure, Journal of Financial Economics 39, 45-69.

[2] Altman, E. (1984) A Further Empirical Investigation of the Bankruptcy Cost Question, Journal of Finance 39, 1067-1089.

[3] Anderson, R. and S. Sundaresan (1996) Design and Valuation of Debt Contracts, Review of Financial Studies 9(1), 37-68.

[4] Anderson, R; S. Sundaresan, and P. Tychon (1996) Strategic Analysis of Contingent Claims, European Economic Review 40, 871-881.

[5] Betker, B. (1995) Management's Incentives, Equity's Bargaining Power, and Deviations from Absolute Priority in Chapter 11 Bankruptcies, Journal of Business 68, 161-183.

[6] Bhattacharya, S. and S. Mason (1981) Risky Debt, Jump Processes and Safety Covenants, Journal of Financial Economics 9(3), 281-307.

[7] Black, F. and J. Cox (1976) Valuing Corporate Securities: Some Effects of Bond Indenture Provisions, The Journal of Finance 31(2), 361-367.

[8] Black F. and M. Scholes (1973) The Pricing of Options and Corporate Liabilities," Journal of Political Economy 81, 637-654.

[9] Cooper. I. and A. Mello (1991) The Default Risk of Swaps, Journal of Finance 46, 597-620.

[10] Das, S. and R. Sundaram (1998) A Direct Approach to the Arbitrage-Free Pricing of Credit Derivatives, Working Paper, Stern School of Business.

[11] Delianedis, G., and R. Geske (1998) Credit Risk and Risk Neutral Default Probabilities: Information about Rating Migrations and Defaults, working paper, UCLA.

[12] Duffie, D. and K. Singleton (1996) Modeling Term Structures of Defaultable Bonds, Working Paper, Stanford University.

[13] Eberhart, A.; W. Moore, and R. Roenfeldt (1990) Security Pricing and Deviations from the Absolute Priority Rule in Bankruptcy Proceedings, Journal of Finance 45, 1457-1469.

[14] Fan, H. and S. Sundaresan (1997) Debt Valuation, Strategic Debt Service, and Optimal Dividend Policy, Working Paper, Columbia University.

[15] Franks, J. and W. Torous (1989) An Empirical Investogation of Firms in Reorganization, Journal of Finance 44, 747-779.

[16] Franks, J. and W. Torous (1994) A Comparison of Financial Recontracting in Distressed Exchanges and Chapter 11 Reorganization, Journal of Financial Economics 35, 349-370. 
[17] Geske, R. (1977) The Valuation of Corporate Liabilities as Compound Options, Journal of Financial and Quantitative Analysis, 541-552.

[18] Hart, O. and J. Moore (1989) Default and Renegotiation: A Dynamic Model of Debt, Working Paper.

[19] Ho, T.S. and R. Singer (1982) Bond Indenture Provisions and the Risk of Corporate Debt, Journal of Financial Economics 10, 375-406.

[20] Huang, J. (1998) A Unified Structural Model for the Valuation of Risky Debt, Working Paper, Smeal School of Business, Pennsylvania State University.

[21] Jensen, M., and W. Meckling (1976) Theory of the Firm: Managerial Behavior, Agency Costs and Ownership Structure, Journal of Financial Economics 3, 305-360.

[22] Jones, E.; S. Mason, and E. Rosenfeld (1984) Contingent Claims Analysis of Corporate Capital Structures: An Empirical Analysis, Journal of Finance 39, 611-625.

[23] Kalay, A (1982) Stockholder-Bondholder Conflict and Dividend Covenants, Journal of Financial Economics 10, 211-233.

[24] Kim, I.J., K. Ramaswamy, and S. Sundaresan (1993) The Valuation of Corporate Fixed Income Securities, Financial Management 117-131.

[25] Lee, I.; S. Lockhead, J. Ritter and Q. Zhao (1996) The Costs of Raising Capital, Journal of Financial Research 1, Spring 1996.

[26] Leland, H (1994) Corporate Debt Value, Bond Covenants, and Optimal Capital Structure, Journal of Finance 49, 1213-1252.

[27] Leland, H. and K. Toft (1996) Optimal Capital Structure, Enogeneous Bankruptcy, and the Term-Structure of Capital Spreads, Journal of Finance 51(3), 987-1019.

[28] Longstaff, F. (1990) Pricing Options with Extendible Maturities: Analysis and Applications, Journal of Finance 45, 935-957.

[29] Longstaff, F. and E. Schwartz (1995) A Simple Approach to Valuing Fixed and Floating Rate Debt, Journal of Finance 50, 789-819.

[30] Mella-Barral, P. and W. Perraudin (1997) Strategic Debt Service, Journal of Finance 52, $531-566$.

[31] A. Mello and J. Parsons (1992) The Agency Costs of Debt, Journal of Finance 47, 1887-1904.

[32] Merton, R. (1974) On the Pricing of Corporate Debt: The Risk Structure of Interest Rates, The Journal of Finance 29, 449-470.

[33] Myers, S. (1977) Determinants of Corporate Borrowing, Journal of Financial Economics 5, 147-175. 
Optimal Dividends \& Risky Debt Valuation ................................... 44

[34] Nielsen, L., J. Saa-Requejo, and P. Santa-Clara (1993) Default Risk and Interest Rate Risk: The Term Structure of Default Spreads, Working Paper, INSEAD, Fontainbleau, France.

[35] Pan, Y. (1994) Design and Valuation of Corporate Securities with Strategic Debt Service and Asymmetric Information, Working Paper, Columbia University.

[36] Smith, C. and J. Warner (1979) On Financial Contracting: An Analysis of Bond Covenants, Journal of Financial Economics 7, 117-161.

[37] Titman, S., S. Tompaidis, and S. Tsyplakov (2000) Agency Costs, Credit Constraints and Default Spreads, Working Paper, University of Texas at Austin.

[38] Warner, J. (1977) Bankruptcy Costs: Some Evidence, Journal of Financial Economics 5, $337-347$.

[39] Weiss, L. (1990) Bankruptcy Resolution: Direct Costs and Violation of Priority of Claims, Journal of Financial Economics 27, 419-444. 